\title{
Understanding Artificial Intelligence Adoption in Operations Management - Insights from the review of academic literature and social media discussions
}

\author{
Purva Grover \\ Information Systems/IT area, Indian Institute of Management Amritsar, India \\ Email: groverdpurva@gmail.com \\ Arpan Kumar Kar \\ Information Systems area, DMS, Indian Institute of Technology Delhi, India \\ Email: arpan_kar@yahoo.co.in \\ Yogesh K. Dwivedi \\ Emerging Markets Research Centre, School of Management, Swansea University, Wales, UK \\ Email: y.k.dwivedi@swansea.ac.uk
}

\begin{abstract}
In this digital era, data is new oil and artificial intelligence (AI) is new electricity, which is needed in different elements of operations management (OM) such as manufacturing, product development, services and supply chain. This study explores the feasibility of Al utilization within an organization on six factors such as job-fit, complexity, long-term consequences, affect towards use, social factors and facilitating conditions for different elements of $\mathrm{OM}$ by mining the collective intelligence of experts on Twitter and through academic literature. The study provides guidelines for managers for Al applications in different components of OM and concludes by presenting the limitations of the study along with future research directions.
\end{abstract}

Keywords

Artificial Intelligence; Technology Adoption; Model of Al utilization; Operation Management 


\section{Introduction}

In the current era of digital transformation, data is considered as the new oil and Artificial Intelligence (AI) is often perceived to be the new electricity which can create value out of this oil. Warner and Wäger (2019) had defined digital transformation as the use of new digital technologies for improving businesses by enhancing customer experience, optimizing operations, creating new business models and many more. These new technologies used in digital transformation can be cloud, blockchain, mobile, Al, Internet of Things and other smart technologies (Duan et al., 2019; Dubey et al., 2020; Hughes et al., 2019; Ismagilova et al., 2019; Wamba and Queiroz, 2020). The usage of technology for digital transformation is determined by organization's attitude towards the technology, perceived usefulness and perceived ease of use (Berlak et al., 2020; Grover et al., 2019). Organizations has been significantly engaged in digital transformation (Burton-Jones et al., 2020).

$\mathrm{Al}$ and big data together are shaping economic, social and political spheres (Duan et al., 2019; Dwivedi et al., 2019; Elish and Boyd, 2018; Wamba et al., 2015; Wamba et al., 2017). Al had been defined as the system's ability to interpret and learn from the digital traces (Haenlein and Kaplan, 2019). Metcalf, Askay and Rosenberg (2019) believes Al can amplify employee's intelligence. Al help employees in overcoming complex situation by presenting diverse and different solutions (Jarrahi, 2018), and subsequently can provide prescriptive inputs in decision making process (Bader and Kaiser, 2019). Employees should focus more on creative work and should learn how to effectively use machines for mundane tasks (Jarrahi, 2018). Morikawa (2017) had pointed firms having highly educated employees and having businesses worldwide expect that Al technologies will have positive impact on businesses.

$\mathrm{OM}$ has been defined in literature as end-to-end organisational management activities and service chains (Karmarkar and Apte, 2007; Subramanian and Ramanathan, 2012) which comprises of several activities such as product designing, process designing, production of goods, planning, scheduling (Zhao et al., 2020), personalized targeting, delivers, customizations, logistics, outsourcing, and many more. The first research gap for the study is the gap pointed by Brock and Wangenheim (2019) that managers have very less knowledge on how to use $\mathrm{Al}$ in their organization's operations. Therefore, this article presents usage of Al in different elements of OM such as manufacturing, product development, services and supply chain.

The second research gap identified for the study are based on the gaps highlighted by Gunasekaran and Ngai (2012), that there is a need to develop OM models for synthesising and converting information into knowledge. Therefore, this study tries to explore the prospect of converting information into knowledge by using $\mathrm{Al}$ on the data and information assets stored within the organization, obtained from digital transformation initiatives. The third gap identified for the study is the open question highlighted by Haenlein and Kaplan (2019), how people and Al supported systems can peacefully coexist with each other. Therefore in this study, eight scenarios in the form of propositions had been explored where authors feel employees and Al powered systems should work in synergy and in a symbiotic relationship, since both are depending on each other and success of Al systems lies in the mutual understanding of both. 
Literature indicates that Al has many advantages over other technological innovations. Firstly, Al can reduce the risk by supporting dynamic capabilities of sensing, seizing, and transforming (Matilda and Chesbrough, 2020). Secondly, Al enlarges the scope of creative thinking (Eriksson et al., 2020). Thirdly, some of the important characteristics supported by Al powered systems were context-awareness, communication capability, embedded knowledge, reasoning capability and self-organisation capability (Romero, Guédria, Panetto and Barafort, 2020). Fourthly, the combination of $\mathrm{Al}$, robotics and big data had been referred to as fourth industrial revolution due the nature of immense impacts these technologies promise. Jarrahi (2018) had suggested Al systems should not be designed with an intention of replacing human contribution but with the intention of augmenting human knowledge and decision making.

The focus of this study is on exploring symbiotic relationship between employees and usage of Al for making effective decision making in different elements of $\mathrm{OM}$. The first research question explored in this study is, how Al can be utilized in OM within an organization environment? For exploring this research question, eight propositions (Proposition 1a, Proposition 1b, Proposition2a, Proposition 2b, Proposition 3a, Proposition 3b, Proposition 4a and Proposition 4b) have been developed. Proposition $1 \mathrm{a}$ and Proposition $1 \mathrm{~b}$ explores the usage of Al within the manufacturing element of $\mathrm{OM}$ for product inspection and quality function deployment. Proposition $2 \mathrm{a}$ and Proposition $2 \mathrm{~b}$ explores the usage of $\mathrm{Al}$ within the product development element of OM for identifying core capabilities and self-learning products. Proposition 3a and Proposition 3b explores the usage of Al within the services elements of OM for personalized targeting and enhancing customer experiences. Proposition $4 \mathrm{a}$ and Proposition $4 \mathrm{~b}$ explores the usage of Al within the supply chain elements of OM for facilitating employee judgement and gathering customers need.

For exploring some of these propositions (Proposition 1a to Proposition 4b), two complementary approaches, academic literature review and social media analytics, suggested by Grover, Kar and Janssen (2019), for determining diffusion of blockchain in different industries had been used. Literature review is a better approach for tracing features and challenges of the technology (in this article technology under consideration is Al) within industry sector (in this article industry sector under consideration is $\mathrm{OM}$ ), whereas for tracing practical implementation of the use cases social media is a better approach (Grover et al., 2019). Banomyong, Varadejsatitwong and Oloruntoba (2019) had pointed out literature review identifies main research themes from the literature available. Social media data had been used in academic literature for event classification (Singh et al., 2019), electoral sentiment analysis (Grover et al., 2019a), reputation estimations (Grover et al., 2019b), communication in emergency situations (Wamba et al., 2019), waste minimisation (Mishra and Singh, 2018) and many more. The two sources of information provide a complementary perspective for our analysis

The remaining sections are organized as follows. Section 2 is dedicated to background study, which had been further divided into three sections OM, digital transformation and Al. Section 3 explains theoretical background, research question and propositions explored in the article. Section 4 illustrates the research methodology adopted for the study. Section 5 presents finding from academic literature review and social media analytics. Section 6 explains and illustrates discussions of insights from academic literature and social media analytics. Subsequently, this is followed by a 
conclusion section which discusses the limitations of the study along with future research directions.

\section{Background Study}

This section contains three subsections, first subsection briefly illustrates OM definition and OM evolution. The second subsection briefly introduces digital transformation and third subsection presents $\mathrm{Al}$ and its tools and techniques.

\subsection{Operations Management (OM)}

Operation management (OM) has been segmented into three modules: "in the door", "out of door" and all the management activities between and beyond "in and out doors" (Karmarkar and Apte, 2007). The first module, "in the doors", takes care of the management activities required for getting appropriate inputs. Sourcing, procurement, supplier selection and logistics are the major activities in this module. The second module, "out of door", takes care of the management activities required for sending goods and services to the customers. This module focuses on three entities distributor, retailer and consumers (Santiváñez and Melachrinoudis, 2020). The third module takes care of all the management activities required between first and second module, requirement elicitation, production, co-creation and process improvements within the firm.

Gunasekaran and Ngai (2012) had briefly illustrated the evolution of OM. In the beginning of the evolution, the objective was on individual customer requirements whereby craftsman and artesian production were the focused strategies. Immediately after the second World War, OM strategies shifted to address objectives like demand for consumer products; total quality management, just-in-time and transfer line production systems. In 1975 to 1985, OM strategies again shifted to focus on objectives like addressing medium volume and variety; quick response manufacturing, computer integrated manufacturing, flexible manufacturing systems and business process reengineering. In 1985 to 1995, OM strategies shifted to focus on objectives like cost reduction, high variety and low volume; lean, agile and physically distributed enterprise environments. In 1995 to 2010, OM objectives were shifted to higher variety and very low volume; outsourcing, global manufacturing and market, agile, internet-enabled supply chain management and third-party logistics. Further 2010 onwards, OM objectives shifted towards global individualized products and services; total global supply chain management, virtual enterprise, radio frequency identification enabled supply chain management, and sustainability. Gunasekaran and Ngai (2012) had also pointed out how OM has evolved from mass production to mass customization through these stages of evolution.

Subramanian and Ramanathan (2012) had categorized use of decision sciences in OM into five broad themes: operation strategy, process and product design, planning and scheduling resources, project management and managing the supply chain. In this article; manufacturing, product development, services and the supply chain component of OM had been explored. Gunasekaran and Ngai (2012) had illustrated that there is lack of quality standards as well there is an inconsistence in producing the quality products across the globe. Morikawa (2017) had pointed out that both manufacturing and nonmanufacturing firms expect favourable impacts of Al on their businesses. Therefore in this study; through proposition 1a, the possibility of using Al systems for product inspection and quality function deployment in proposition $1 \mathrm{~b}$ has been explored. 
Subramanian and Ramanathan (2012) had defined product development as drawing up the specifications for the making of the product appropriated to the customers' needs. Proposition 2a explores the core capabilities of the organizations on real time basis for product development through Al. Gunasekaran and Ngai (2012) had pointed out that there is lack of customer knowledge on the product, therefore in proposition $2 \mathrm{~b}$ the usage of multi-agent distributed agents for self-learning products had been explored. Further in proposition $3 \mathrm{a}$ and $\mathrm{3b}$, the use of $\mathrm{Al}$ for recommender systems for personalized targeting and the use of intelligent chatbots (like Amazon's Alexa or Apple's Siri) for customer relationship management has been discussed.

Supply chain encompasses all activities such as managing inventory, logistics, reverse logistics, outsourcing (Queiroz and Wamba, 2019; Subramanian and Ramanathan, 2012). Supply chain can divided into two parts upstream supply chain and downstream supply chain. Popular decision problems in upstream supply chain is the selection of supplier (Kar, 2014; Kar, 2015). Gunasekaran and Ngai (2012) had illustrated there is lack of fair practices in procurement and merit-based supplier selection. Therefore, in proposition $4 \mathrm{a}$, the usage of Al for facilitating human judgement had been explored. Subsequently in proposition $4 \mathrm{~b}$, usage of $\mathrm{Al}$ for gathering customers need had been explored.

\subsection{Digital Transformation}

Romero, Guédria, Panetto and Barafort (2020) had characterised digital transformation as a change of paradigm from computer-aided technologies to smart systems. ElMassah and Mohieldin (2020) had highlighted digital transformation within an organisation is needed for decision making purposes, whereas Bordeleau, Mosconi and de Santa-Eulalia (2020) had highlighted digital transformation can leverage business intelligence and analytics within an organization.

Digital transformation had increased customer experiences and centricity (Taylor et al., 2019). Digitization had evolved new marketing concepts such as value propositions and co-creation (Taylor et al., 2019). Digitalization improves audit quality and firm governance (Manita et al., 2020). Zangiacomi, Pessot, Fornasiero, Bertetti and Sacco (2020) had highlighted some of the practices for digital transformation. Firstly, there is a need to understand how using digital technology company business model can be changed (Job-fit). Secondly high level management should have an awareness of the digital technology implications on the organization and employees (perceived consequences and complexity). Berlak, Hafner and Kuppelwieser (2020) had highlighted employee's acceptance behaviour plays a significant role in generating productivity from digital transformation (affect towards use). Behavioural intention has been pointed out as one of the deciding factor of digital system use. Berlak, Hafner and Kuppelwieser (2020) had highlighted key factors during digital transformation: attitude towards technology; perceived usefulness; desired behaviour; and perceived ease of use impact this outcome more than anything else.

\subsection{Artificial Intelligence (AI)}

Al has been defined as a system's ability to learn from external data correctly and apply the learnt learnings for achieving specific goals and tasks (Haenlein and Kaplan, 2019). Such learning by the system may be supervised, semi-supervised or unsupervised (Kar, 2016). Kumar, Rajan, Venkatesan and Lecinski (2019) had defined Al as a tool for endless options and information that can be narrowed down to personalized targeting (Kumar et al., 2019). Similarly Jarrahi (2018), had also pointed Al as a set of tools, 
techniques and algorithms that is situated within an organizational context for the welfare of the organization and its stake-holders. Algorithms of Al typically attempt to mimic the way organisms in nature operate to meet their basic needs like finding food through foraging, reproduction and survival amid changing ecosystem (Kar et al., 2016; Chakraborty and Kar, 2017).

Haenlein and Kaplan (2019) had suggested two ways in which Al can be classified, first on the basis of evolutionary stages of $\mathrm{Al}$ and second on the basis of intelligence type exhibited by an Al system. On the basis of evolutionary stages, Al can be split into three types such as artificial narrow intelligence, general intelligence and super intelligence. The intelligence exhibited by an Al system can further be cognitive, emotional or social intelligence. Thus on the basis of this nature of intelligence; Al systems can be classified as analytical, human-inspired or humanized Al respectively.

Some of the popular algorithms in Al are: bio inspired algorithms like neural networks and genetic algorithms (Kar, 2016); swarm intelligence (Chakraborty and Kar, 2017); algorithms for unstructured data analysis like natural languages, images and video processing (Grover and Kar, 2017; Jarrahi, 2018) and cognitive computing to make sense of such unstructured data (Gupta et al., 2018). While some of the core algorithms are built out of the same building blocks, based on objectives and nature of data, they undergo significant degree of evolution. The algorithms which help the machines in understanding and analysing the language used by humans comes under the category of natural language processing algorithms. The algorithms which enables the machines to learn from the available data and operate, often without human intervention, on new contexts comes under the category of machine learning algorithms.

The algorithms which facilitate inspection and analysis of images and videos comes under the category of computer vision algorithms. Al-based decision making depends on five factors: decision search space, alternative set size, interpretation of processes and outcomes, decision-making speed and replicability (Shrestha, Ben-Menahem and von Krogh, 2019). Bader and Kaiser (2019) had pointed out when human and algorithmic intelligence become unbalanced; performative effects results in deferred decisions, repetitive work and manipulations as well.

In the Industry 4.0 era, Huang, Rust and Maksimovic (2019) had illustrated how Al is expanding from addressing mechanical and repetitive tasks to thinking and analytical tasks. Kühl, Mühlthaler and Goutier (2019) had pointed out how Al can be used for extracting stakeholder needs for the purpose of stakeholder-oriented marketing. Further, Kumar, Rajan, Venkatesan and Lecinski (2019) had pointed Al provides prediction to managers on customer management and branding practices in developed and developing countries both. Overgoor, Chica, Rand and Weishampel (2019) had pointed out Al had been useful in many applications such as automating cars, customer service responses and many more.

\section{Theoretical background, Research Question and Proposition}

This section had been divided into the two subsections. The first section introduces the conceptual model of personal computing utilization, first proposed by Thompson, Higgins and Howell in 1991, which authors has extended for Al utilization in different components of OM. The second section introduces the research question and proposition explored in this article.

\subsection{Model of PC utilization for Al}


This section briefly illustrates six factors of PC utilization models customized for Al utilization such as jobfit, complexity, perceived consequences, affect towards use, social factors and facilitating conditions. Table 1 briefly presents Al utilization factors for an organization.

\section{Table 1. Factors for Al utilization in an organization}

\begin{tabular}{|l|l|}
\hline Factors & Explanation \\
\hline Job-fit & $\begin{array}{l}\text { Belief of an individual that using the Al technology will enhance their } \\
\text { job performance. }\end{array}$ \\
\hline Complexity & Perceived difficulty in understanding and using the Al technology. \\
\hline Perceived consequences & Choices made by organizations for maximum rewards. \\
\hline Affect towards use & $\begin{array}{l}\text { Measurement of the feelings (joy, pleasure, elation, depression, } \\
\text { disgust or hate) towards Al implementation or usage. }\end{array}$ \\
\hline Social factors & $\begin{array}{l}\text { Influence of Al perception among other players and market } \\
\text { competitors }\end{array}$ \\
\hline Facilitating conditions & Factors easing the use of Al in an organization \\
\hline
\end{tabular}

\subsubsection{Job-fit}

Thompson, Higgins and Howell (1991) had illustrated job fit measures the belief of an individual that using the technology will enhance their job performance. For example, a professional may feel using Al for product inspection will increase product quality as compared to human inspection. A manager may have a belief deploying Al algorithm for quality checking will reduce defect rates. The board of directors of the Multi-National Corporations (MNC) may feel so many employees join and leave the organizations each year, therefore managers should consult an Al system for identifying the core capabilities of an organisations and manage the tacit knowledge within the organizations. Similarly MNCs feel that employees have a learning rate and capacity, which is often surpassed by Al. Thus speed of growth may be perceived to be surpassed by deploying Al instead of deployment of employees wherever possible.

\subsubsection{Complexity}

Thompson, Higgins and Howell (1991) had defined complexity as the perceived difficulty in understanding and using innovation (in this article the innovation under consideration is the usage of Al within OM components: manufacturing, product development, services and supply chain). Professionals always have an inclination towards the technology which can be used without any effort, Davis (1989) had named this factor as perceived ease of use. High complex activities in OM could have improved outcome when Al may process a high diversity and volume of information, to meet desired outcomes.

\subsubsection{Perceived consequences}

Thompson, Higgins and Howell (1991) had illustrated individuals makes the choices in which they feel they will get the maximum reward. To explain further on the basis of expectancy theory and Thompson, Higgins and Howell (1991) explanation if the usage of Al is more attractive and brings more benefit to workers, professionals, corporates, organizations and other entities; subsequently the utilization of Al powered systems within an organization will also increase. Some of the perceived consequences highlighted by Thompson, Higgins and Howell (1991) are enhanced job satisfaction and job flexibility. 


\subsubsection{Affect towards use}

The concept of "affect" illustrated by Thompson, Higgins and Howell (1991), is captured in this study as the measure of the feelings (joy, pleasure, elation, depression, disgust or hate) towards Al usage or implementation processed by the workers, professionals, corporates, organizations and other entities. Potential user of Al may have the feeling of joy, pleasure and elation when using Al, mundane and repetitive tasks such as inspection, customization and many more, can be done better and the user gets more time to focus on innovative and creative tasks. Potential users of Al may have the feeling of depression, disgust or hate when they think, using Al many tasks are getting automated, and therefore in the near future, organizations will replace employees with machines.

\subsubsection{Social factors}

Thompson, Higgins and Howell (1991) had pointed out that social factors influence behavioural intentions. Habits are direct and indirect determinants of the behaviour. Taking into account today's era and by taking into account social factors explanation illustrated by Thompson, Higgins and Howell (1991), for this article social factors can been divided into the two parts. The first is how organizations and corporates perceive Al technologies. The second part focuses on what should organizations do with the help of Al in order to remain in the race with their competitors.

\subsubsection{Facilitating conditions}

Thompson, Higgins and Howell (1991) had defined facilitating condition as factors in the environment which will ease the implementation and use of the Al powered system within an organization environment. One of the facilitating conditions which can really support Al implementation is investments made in high quality and user-friendly computing infrastructure like data warehouses and databases maintained in the organizations. Further training users to use such infrastructure would be necessary. Such investments would require support from the leadership. Using the data stored in data warehouses and databases Al algorithms can be trained for the future use (availability of training dataset) and create value for the business, based on the perceptions of the top leadership.

\subsection{Research question and proposition}

In this article, symbiotic relationship between Al systems among workers, professionals, corporates and organizations for decision making in different functions of $\mathrm{OM}$ had been explored. The research question explored in this article is as follows: how can Al be utilized in OM within an organization environment? Al utilization in OM can increase organization efficiency, return on investment, quality, innovation, customer satisfaction, employee empowerment and many more. Due to the limit of the article length in this article; only eight propositions had been explored. Propositions $1 \mathrm{a}$ and propositions $1 \mathrm{~b}$ focus on manufacturing component of the OM for product inspection and quality function deployment.

Sun (2019) had illustrated deep learning can be used for visual recognition in audits. According to him deep learning helps in information identification and gives judgment support in audits (Sun, 2019). Therefore, on the basis of the readings till now, authors propose a positive relationship of using Al for product inspection and deploying quality function. 
Proposition 1a: Al usage for product inspection enhances product quality as compared to human inspection.

Proposition 1b: Implementing Al for quality function deployment reduces defect rates.

Wang, Sun, Niraj, Chung and Su (2019) had pointed out that for decision making it is essential to understand the process of consumer decision making. Carrillo, Druehl and Hsuan (2015) had pointed out innovation is needed in product development and process management from time to time. Mou and Robb (2019) had pointed out that considerably less research had been done on real time labour allocation with respect to changing customer and store needs. Therefore, authors hold the view that Al algorithms can be deployed on enterprise resource planning system. Such systems facilitates the replication and propagation of innovation and digital initiatives across the enterprise. These algorithms may further help the organizations in identifying core capabilities of an organisation which will subsequently lead to innovation in product development and services. For this exploration proposition $2 \mathrm{a}$ had been framed positive.

Proposition 2a: Automating the Al algorithm execution on enterprise resource planning system (ERP system) enables innovation by identifying the core capabilities of the organisations on real time basis for product development.

Singh and Tucker (2017) had pointed out that by going through customer reviews, designers can have a deeper understanding of market needs. Lei and Moon (2015) based on design parameters and market data had identifies how Al can be used for product positioning which allows users to explore alternative scenarios during product development. Therefore, authors of the study have the opinion that firms which are working in different places across the world can depend on Al algorithms for learning from past operational data. Proposition $2 \mathrm{~b}$ proposes Al facilitates autonomous self-learning products and their development.

Proposition 2b: Using multi-agents and distributed agents with Al algorithms in product design facilities the creation of autonomous, self-learning products.

Customer orientation, personalization and customization had always been the key for winning the competition in marketplaces (Alt et al., 2019). Therefore, authors hold the positive view of using Al driven recommender systems for personalized customer targeting will enhance customer experiences. Thus proposition $3 \mathrm{a}$ and proposition $3 \mathrm{~b}$ explores this relationship, respectively. Aligon, Gallinucci, Golfarelli, Marcel and Rizzi (2015) highlighted how in a three phase recommendation approach using Al; the information of individual user is used along with the activities of similar users, while personalised recommendations are made.

Proposition 3a: Using inbuilt recommender systems (by Al algorithm) for personalized targeting of digital advertisement can increase return on investment.

Proposition 3b: Using Al systems like chatbots for customer relationship management enhances customer experiences as compared to human engagement. 
Peiris, Jung and Gallupe (2015) had pointed out how for the growth of organisations, they need to manage their supply chains effectively. Supply chain coordination and information sharing have a direct effect on organizational performance (DuHadway et al., 2019; Lee and Fernando, 2015; Liu et al., 2020). Muggy and Stamm (2020) had pointed out supply chain operations depends on beneficiaries and services needed. On the basis of such literature, authors also feel usage of Al in upstream supply chain will increase the horizon of the employees and will facilitate the human judgement. Using Al in downstream supply chain will help the organizations in reaching to more customers and retaining them.

Proposition 4a: Usage of Al algorithms in upstream supply chain in real time increases the horizon of the employee and facilitate the human judgements.

Proposition 4b: Usage of Al algorithms in downstream supply chain in real time increases the probability of reaching the customers and facilitate in gathering the customers needs.

\section{Research Methodology}

The study tries to explore the research question, how Al could be utilized in OM within an organization environment, based on reviewing two sources of information, namely academic literature and social media discussions. For exploring this research question, the methodology suggested by Grover, Kar and Janssen (2019) combining academic literature review and social media analytics had been used to capture the collective intelligence residing in these two bodies of knowledge. Similar methodology has been utilised by a recent study published by (Karami et al., 2020)

The review of academic literature has been used because of the following reasons (Webster and Watson, 2002): firstly, literature review facilitates theory development. Secondly, literature review help us in finding the area where a plethora of research exists. Thirdly, literature review also help us in finding the area where more research is needed. Finally, systematic literature review can help in tracing the birth of the technology from the birth and subsequently help us in identifying the practical and conceptual implementation of the technology (Hart, 1998).

Social media analytics had been used as second method because of the following reasons: firstly, literature indicates from user-generated content present on social media technological frame of the users towards the technology can be derived (Grover et al., 2019). Secondly user generated content present on the social media platform can help in identifying the popular players associated with the technology. Thirdly, for a domain like technical Al, social media discussions allow us to obtain updated information on the new uses of the emerging technology directly from practice.

Figure 1 explains the systematic literature review process followed for selecting research articles. Below

is the query used for searching the article on Scopus. Major themes occurring in the article are: manufacturing, product development, services and supply chain (Wooten and Tang, 2018). Figure 2 presents the number of articles selected in each stage of systematic literature review process.

Scopus Query: ( TITLE-ABS-KEY ( "operations management" ) OR TITLE-ABS-KEY ( "artificial intelligence" )) AND ( LIMIT-TO ( SRCTYPE, "j" )) AND ( LIMIT-TO (DOCTYPE, "ar" )) AND ( LIMIT-TO ( PUBYEAR, 
2019 ) OR LIMIT-TO ( PUBYEAR, 2018 ) OR LIMIT-TO (PUBYEAR, 2017 ) OR LIMIT-TO ( PUBYEAR, 2016 ) OR LIMIT-TO ( PUBYEAR, 2015 ) OR LIMIT-TO (PUBYEAR, 2014 ) OR LIMIT-TO ( PUBYEAR, 2013 ) OR LIMIT-TO ( PUBYEAR, 2012 ) OR LIMIT-TO (PUBYEAR, 2011 ) OR LIMIT-TO (PUBYEAR, 2010 ) )

\begin{tabular}{|c|c|c|}
\hline $\begin{array}{l}\text { 1. Specify Research } \\
\text { Questions - How } \\
\text { artificial intelligence can } \\
\text { be utilized in operations } \\
\text { management within an } \\
\text { organization } \\
\text { environment? } \\
\text { 2. Develop Review } \\
\text { Protocol - (a) Identify } \\
\text { relevant studies by } \\
\text { searching Scopus } \\
\text { database on search } \\
\text { term "operation } \\
\text { management" OR } \\
\text { "artificial intelligence" } \\
\text { in title, abstract and } \\
\text { keywords. } \\
\text { 3. Validate Review } \\
\text { Protocol - The review } \\
\text { protocol had been } \\
\text { reviewed formally by } \\
\text { experts and the results } \\
\text { of it were considered by } \\
\text { the review team. }\end{array}$ & $\begin{array}{l}\text { 4. Identify Relevant } \\
\text { Research - Search term } \\
\text { "operations } \\
\text { management" OR } \\
\text { "artificial intelligence" } \\
\text { had been searched in } \\
\text { title, abstract and } \\
\text { keywords in Scopus } \\
\text { database on } 20 \text { April } \\
\text { 2018. } \\
\text { 5. Select Primary } \\
\text { Studies - Irrelevant } \\
\text { studies on basis of title, } \\
\text { abstract and } \\
\text { inclusion/exclusion } \\
\text { criteria were rejected. } \\
\text { 6. Assess Study Quality } \\
\text { - Only journal } \\
\text { publication were } \\
\text { considered for the } \\
\text { review. } \\
\text { 7. Extract Required } \\
\text { Data - Article and } \\
\text { source information } \\
\text { 8. Synthesise Data - } \\
\text { Descriptive information } \\
\text { had been presented. }\end{array}$ & $\begin{array}{l}\text { 9. Write Review Report } \\
\text { - Findings and } \\
\text { discussion section } 3 \\
\text { presents the insights of } \\
\text { literature on } \\
\text { Propositions } 1 a, 1 b, 2 a \text {, } \\
2 b, 3 a, 3 b, 4 a \text { and } 4 b . \\
\text { 10. Validate Report - } \\
\text { The review had been } \\
\text { internally validated. }\end{array}$ \\
\hline
\end{tabular}

Figure 1. Systematic literature review process followed 


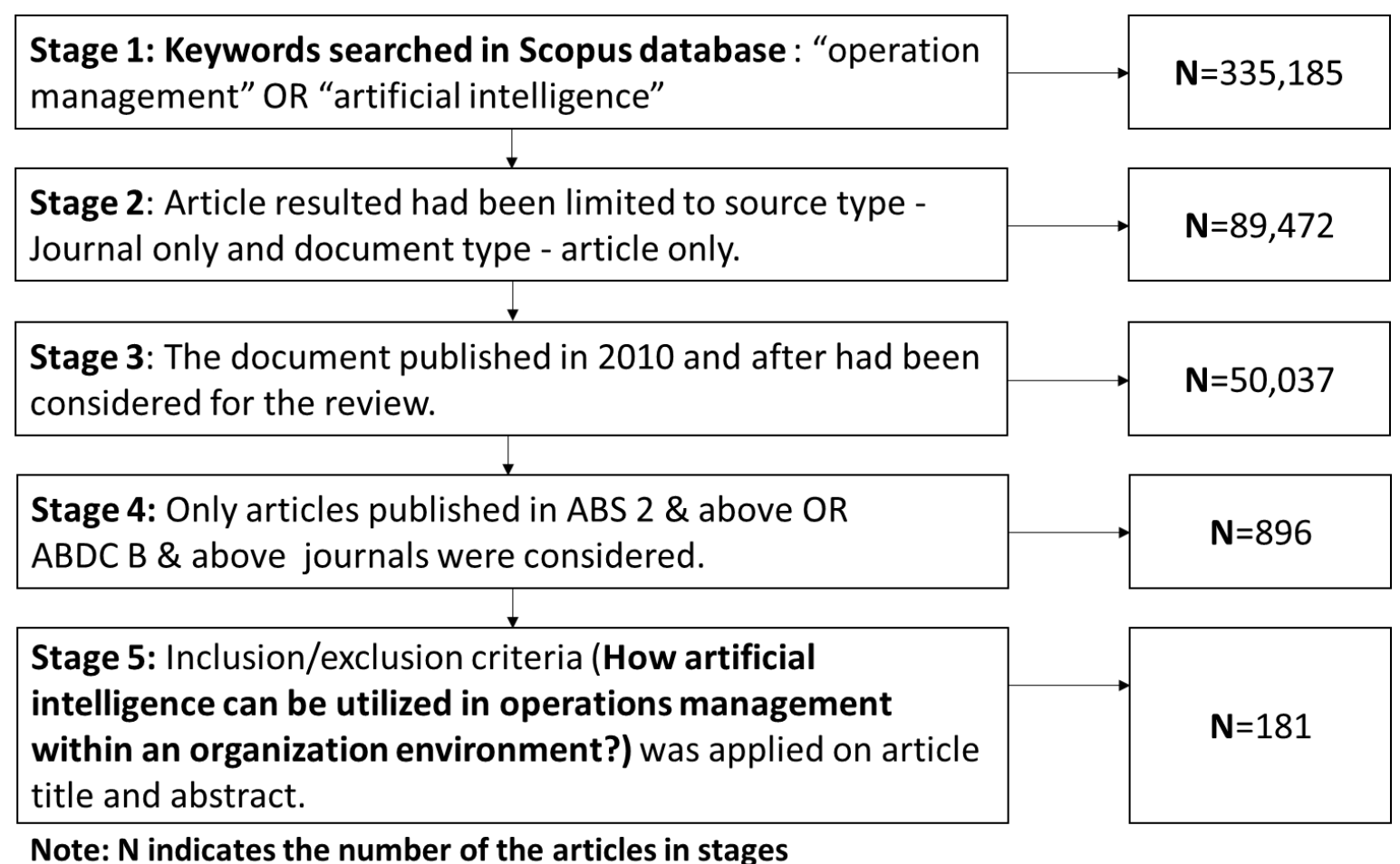

Figure 2. Stages for selection of the articles for the literature review, $\mathrm{N}$ indicates the number of the articles at each stage

Evangelos, Efthimios and Konstantinos (2013) had suggested four parameters for extracting the data from Twitter. These were (a) selection of the search term (what); (b) author's identity (who); (c) location (where); and (d) time (when) for which you want to extract the data for. Therefore, data collection step tries to extract data from Twitter using four questions, what, when, where and who had written something on Twitter related to Al or OM. The second steps structure the data for further processing. The third step tries to analyse the data using social media analytics approaches (Rathore et al., 2017) such as sentiment analysis, text analytics and network analytics. The last step tries to present the findings. For data extraction from Twitter, two API are available (Kumar et al., 2014). One is the "Search API" and another one is "Streaming API".

Twitter provides results in text file as JavaScript Object Notation (JSON) document. JSON is the popular format and had been widely used on the web. Literature indicates managing text archive is very difficult and suggests MongoDB, NoSQL database can be used for storing the tweets (Kumar et al., 2014). To analysed data using SQL tools such as R, excel and SPSS, there was the need for transforming data from JSON format to relational format. Data pre-processing converts the raw data (i.e. JSON format) into clean structured data set. Python can analyse the data in JSON as well as SQL format. The pre-processing step had been divided into four sub-steps of data transformation, storing of data, data reduction and data cleaning.

The tweets extracted using Twitter API is in the unstructured JSON format, of key value pair. To best of our knowledge there were very less tools which can analyse the data in JSON format, therefore there was a need to convert the key value pair into structured relational format. Therefore, the extracted data has 
been converted from JSON format to two dimensions, relational format. In order to define a structure for the tweets data frame had been used. For creating data frames "Pandas Data Analysis library" in Python has been used. It supports information extraction from data frames. After data extraction using the python script the tweets had been structured and stored in the table format.

In order to increase accuracy and decrease processing time, data set had been reduced to 23 attributes. The variables can be grouped into two domains; tweet and user variables. For each tweet fields like creation date, content, author, language in which the tweet had been created is being captured. The tweet is an informal unstructured content and may contain a mix of text, hyperlinks, images, videos, hashtags and other media. Therefore, for extracting meaningful information from tweets, cleaning is required. Firstly, anything other than English letters had been removed. Secondly, all the extra white spaces and hyperlinks have been removed followed by removing references to other screen names. For data normalization words were transformed into lowercase in the tweets. Stemming reduces derived words to well defined stems for improved analysis. For example, words like thoughtful had been reduced to thought, exciting to excite, so that uniformity of analysis can be achieved. For some of the text analysis; tokenization process had also been followed for creating tokens for the words.

Descriptive analysis provides insights into data by applying simple functions such as count, sum, mean, median and mode. Descriptive analysis had been extensively used for briefing, over viewing and summarizing data. Descriptive analysis is the first step in various data analysis process of brand personality, consumer analysis, tourism marketing and inventory management (Dolnicar and Ring, 2014; Erevelles et al., 2016; Huang and Van, 2014; Milas and Mlacic, 2007). Descriptive analysis helps in computing and presenting basic descriptive statistics of the dataset, such as the number of individual users, number of tweets, types of tweets, frequency of @mention and hashtags. Word clouds present popular words in the tweets (Nooralahzadeh et al., 2013). If users retweet the tweet, the tweet will be posted in their tweet stream and their followers will be able to see it. Replying enables users to tweet a reply to the author of the original content. Twitter counts messages, retweets, and likes in order to single out important or trending tweets. Hashtags facilitates the sharing of the tweet across broader community (Chae et al., 2015).

Text analytics extracts information from textual data. User generated content on social media, emails, blogs, open ended questions in the survey responses, news, corporate documents, transactions logs are some of the examples of the textual data. Text analytics converts large volumes of text into meaningful numbers and summaries. Some of the text analytics methods which had been used in this article: sentiment analysis, word cloud and content analysis. Sentiment analysis is the process of categorizing tweets on the basis of the polarity and emotion (Zhang et al., 2016). Polarity consists of three categories: positive, negative, and neutral. Sentiment consists of eight categories; namely; anger, trust, anticipation, surprise, disgust, sadness, fear and joy. Content analysis converts qualitative data into quantitative data on the basis of the semantics (Kassarjian, 1977). The quantitative data can be used for statistical testing which subsequently enhances the reliability, validity and generalizability of the analysis (Krippendorff, 2004). The reliability and validity is also improved by depending on more than one judge to code the categories and map the categories such that consensus is achieved and inter-coder distance among ratings are minimized. 
For analyses of the data, three software had been used extensively, these were Python, R Studio and Excel. The data from Twitter was extracted using search API, by searching the term "\#operationsmanagement" AND "\#artificialintelligence" (what). The data is being extracted on daily basis for three months starting from September 7, 2019 to December 7, 2019 (when). Twitter had allowed us to extract 4000 to 10000 tweets on daily basis. In terms of location study tries to capture tweets globally. User profiles related to professionals, corporates, organizations and data workers had been considered as experts for the study and their opinion had been extracted from Twitter.

\section{Findings}

This section had been divided into two sub sections, first sub section present insights from academic literature on eight propositions with respect to six factors such as job fit, complexity, perceived consequences, affect towards use, social factors and facilitating conditions on Al utilization in OM. The second sub section is on insights from the expert opinion available on social media on Al utilization in different components of OM such as manufacturing, product development, services and supply chain.

\subsection{Insights from academic literature}

Among 181 selected research articles for literature review there was no single article on Al utilization for product inspection and quality function deployment. Abrahams, Jiao, Wang and Fan (2012) had proposed that using social media analytics automotive quality management can be improved. On basis of the near like cases, authors had explored Al utilization for product inspection (Proposition 1a) on six factors, job fit, complexity, perceived consequences, affect towards use, social factors and facilitating conditions, had been summarized in Table 2.

Proposition 1a: Al usage for product inspection enhances product quality as compared to human inspection.

Proposition 1a proposes the usage of Al powered system for product inspection. According to literature, Al system will enhance the product quality as compared to human inspection. On the basis of the academic literature it is true for big size products which cannot be handle easily by an employee (Job fit). When considering the big size products, the techniques such as image processing or robot inspection can be used. For implementing such techniques within organization lot of investment is needed from organizations for building IT infrastructure (Complexity). Once the investment has been done; automation of the processes (Perceived consequences) will make the organization management happy for maintaining consistency in quality standards (Affect towards use). The complexity involve in big size inspection through image processing is that smaller dataset will be available for training purposes which may lead to bias (Complexity).

Proposition 1b: Implementing artificial intelligence algorithm as the quality function deployment reduces defect rates. 
Proposition $1 \mathrm{~b}$ illustrates the usage of Al for quality function deployment in the light of the academic literature. It seem that the usage of Al for quality function deployment is beneficial in large scale production systems (Job fit), where employee gets exhausted due to repetitive physically draining activities in large scale production. There machine alertness can be used (Affect towards use) for enhancing and maintaining consistency in products standards (Perceived consequences) across the organisation. Organisations which are maintaining real time performance dashboards at present can upgrade their systems by deploying Al algorithms for quality function and train their internal employees to use these systems effectively (Facilitating conditions). Al utilization for quality function deployment had been summarized in Table 2.

Table 2. Proposition $1 \mathrm{a}$ and Proposition $1 \mathrm{~b}$ discussion on Al utilization factors

\begin{tabular}{|l|l|l|}
\hline $\begin{array}{c}\text { Al utilization factor } \\
\text { in an organization }\end{array}$ & \multicolumn{1}{|c|}{ Proposition 1a } & \multicolumn{1}{|c|}{ Proposition 1b } \\
\hline 1. Job fit & Economical for big size products. & $\begin{array}{l}\text { Beneficial for large scale } \\
\text { productions. }\end{array}$ \\
\hline 2. Complexity & $\begin{array}{l}\text { Large productization initiatives may } \\
\text { lead to smaller datasets in which } \\
\text { bias may occur. }\end{array}$ & $\begin{array}{l}\text { Implementation in real time basis, } \\
\text { updating the quality functions on } \\
\text { each instance dynamically. }\end{array}$ \\
\hline $\begin{array}{l}\text { 3. Perceived } \\
\text { consequences }\end{array}$ & $\begin{array}{l}\text { More depended on machines; } \\
\text { Automating the inspection. }\end{array}$ & $\begin{array}{l}\text { Reduces defect ratio. Enhances } \\
\text { product quality standards. }\end{array}$ \\
\hline $\begin{array}{l}\text { 4. Affect towards } \\
\text { use }\end{array}$ & $\begin{array}{l}\text { Organization feeling happy because } \\
\text { of automation, but automation } \\
\text { increases the investment } \\
\text { infrastructure. }\end{array}$ & $\begin{array}{l}\text { Machines alertness when humans } \\
\text { exhausted. }\end{array}$ \\
\hline $\begin{array}{l}\text { 5. Social factors } \\
\text { Worker communities less open to } \\
\text { experiments and want to use old } \\
\text { technologies only. }\end{array}$ & $\begin{array}{l}\text { Lack of acceptance of machine } \\
\text { monitoring culture within } \\
\text { organisation at present. }\end{array}$ \\
\hline $\begin{array}{l}\text { 6. Facilitating } \\
\text { conditions }\end{array}$ & $\begin{array}{l}\text { Updated IT infrastructure; training } \\
\text { employees, executive support }\end{array}$ & $\begin{array}{l}\text { Real time performance dashboards, } \\
\text { training user groups }\end{array}$ \\
\hline
\end{tabular}

Naderpour, Lu and Zhang (2014) had pointed out that situation awareness is needed for performance improvement within an organization; therefore, they had proposed situation awareness support systems using dynamic bayesian networks. Authors of the article also hold the same opinion, i.e., situational awareness plays a key role in performance improvement, therefore proposition 2a had been proposed, Al algorithms can be applied on the organization ERP system for identifying the core capabilities of the organization.

Proposition 2a: Automating the Al algorithms execution on the ERP system enables innovation by identifying the core capabilities of the organizations on real time basis for product development.

There were many articles in literature which were discussing on organization decision making, planning and activities scheduling (Petrovic, 2019). Therefore, in consideration of such existing literature, proposition 2a, had been discussed on Al utilization factors, which had been summarized in Table 3. Implementation of Al algorithm on ERP system is best suited for MNC 
organizations having offices in multiple places (Job fit) and having large number of employees. The biggest hurdle in this is selecting appropriate data sources for identifying the core capabilities and without violating any ethical or legal issues (Complexity). The biggest advantage of this is it will may reduce the risk level of product failure (Perceived consequences). However Al implementation on organizations using ERP, can have the additional satisfaction that they are using resources fully and appropriately (Affect towards use).

Proposition 2b: Using multi- agent distributed agents with Al algorithms in product design facilities the creation of autonomous, self-learning products.

Self-learning products from multi-sites is new in the literature but there are evidences in literature where scholars had talked learning from single machine. The biggest problem in learning in distributed environment is data available in different form (variety) has to be analysed, at the same time data is being generated at high volume and velocity (Complexity), therefore Al algorithm has to be trained considering 3V's, volume, variety and velocity of big data (Queiroz and Telles, 2018; Wamba et al., 2015; Wamba and Mishra, 2017). Learning across distributed sites will help organizations in making and maintaining global standards (Perceived consequences). Distributed connected servers across multi sites and transfer learning across multi sites may help self-learning of multi- agent (Facilitating conditions). Al utilization factors for Proposition $2 \mathrm{~b}$ had been summarized in Table 3.

Table 3. Proposition 2a and Proposition 2b discussion on Al utilization factors

\begin{tabular}{|c|l|l|}
\hline $\begin{array}{l}\text { Al utilization factor in an } \\
\text { organization }\end{array}$ & Proposition 2a & Proposition 2b \\
\hline 1. Job fit & $\begin{array}{l}\text { Employees performance may be } \\
\text { adversely impacted. Better suited } \\
\text { for MNC organizations. }\end{array}$ & $\begin{array}{l}\text { Products having low return on } \\
\text { investment. }\end{array}$ \\
\hline 2. Complexity & $\begin{array}{l}\text { Selection of data sources for } \\
\text { appropriate business objectives } \\
\text { which is both ethical and legal to } \\
\text { be used. }\end{array}$ & $\begin{array}{l}\text { Analysing big data which can be } \\
\text { categorized by 3V's, volume, } \\
\text { variety and velocity. }\end{array}$ \\
\hline 3. Perceived & $\begin{array}{l}\text { Reduce the risk level of product } \\
\text { failure. }\end{array}$ & $\begin{array}{l}\text { Global standards can be } \\
\text { developed and adhered to. }\end{array}$ \\
\hline 4. Affect towards & $\begin{array}{l}\text { Satisfaction of how the } \\
\text { organisation resources are being } \\
\text { used appropriately and effectively. }\end{array}$ & $\begin{array}{l}\text { Implementation may lead to } \\
\text { successful product which is } \\
\text { acceptable by more consumers. }\end{array}$ \\
\hline 5. Social factors & $\begin{array}{l}\text { Rigidity of the organization } \\
\text { hierarchy and employees }\end{array}$ & Consumer's privacy. \\
\hline 6. Facilitating & $\begin{array}{l}\text { Leadership support of data } \\
\text { collection, having observable } \\
\text { outcomes. }\end{array}$ & $\begin{array}{l}\text { Distributed connected servers } \\
\text { across multi sites. Transfer } \\
\text { learning across multi sites. }\end{array}$ \\
\hline
\end{tabular}

Bauer and Nanopoulos (2014) had pointed out recommender systems as an aid for customers in decision making process for purchase of products and services, further they had proposed recommendations 
based on implicit customer feedback by applying matrix factorization. Bhatti, Huang, Wu, Zhang, Mehmood and Han (2019) had purposed a recommender system based on diseases patterns for managing enterprise healthcare. Therefore, proposition 3a had proposed of using recommender system for personalized targeting.

Proposition 3a: Using inbuilt Al based recommender systems for personalized targeting of digital advertisement can increase return on investment.

Recommender systems is best suited for the organizations which have the mandate of converting larger pool of potential customers to consumers for specific products (Job fit). The biggest difficulty faced in implementing recommender systems is where to apply and how accurately it will make the suggestion for a particular customer (Complexity). The successful implementation of recommender systems may lead to increase in return on investment (Perceived consequences). With the help of recommender system organizations can bring mass customization in the marketplace which subsequently will lead to more happy customers (Affect towards use). Such customers can be within the organization (internal stakeholders) or outside the organization (External stakeholders). Implementation and adoption of the recommender systems can be made easy by looking at previous trends and user groups (Facilitating conditions). To best of our knowledge only social factors which limit the success of recommender system is when customers ignores the suggestions made by recommender system or finds the information difficult to consume. Al utilization factors for Proposition 3a had been summarized in Table 4.

Oh, Byon, Jang and Yeo (2015) had highlighted prediction can be made from available data by applying parametric approaches such as linear regression and non-parametric approaches such as Al and pattern searching. Therefore now days there has been the trend where organizations train the Al systems such as Amazons Alexa and Apple's Siri for customer relationship management (Facilitating conditions) and authors feels customer relationship management through Al powered machine enhances customer experiences as compared to human engagement, proposition $3 \mathrm{~b}$. Under the influence of evidences present in the literature results for proposition $3 \mathrm{~b}$ on Al utilization factors had been summarized in the table 4.

Proposition 3b: Using Al systems like chatbots for customer relationship management enhances customer experiences as compared to human engagement.

Al powered customer relationship management is best suited for organizations having large pool of consumers (Job fit). Literature holds both type of evidences where using Al system for customer relationship management may enhanced consumer experiences (Perceived consequences) and subsequently leads to increase in loyalty of the consumers towards organization (Affect towards use). There are evidences in the literature where consumers had not appreciated conversation with Al system, and such encounters are often driven by cultural background of the users (Social factors). To best of our knowledge and to the extent literature had been read by us, the biggest hurdle faced in using Al systems for customer relationship management in an organization is that Al systems cannot handle the situations which is new to them (Complexity). 
Table 4. Proposition $3 a$ and Proposition $3 b$ discussion on Al utilization factors

\begin{tabular}{|c|c|c|}
\hline $\begin{array}{l}\text { Al utilization factor in an } \\
\text { organization }\end{array}$ & Proposition 3a & Proposition $3 b$ \\
\hline 1. Job fit & $\begin{array}{l}\text { Larger pool of potential customers } \\
\text { and management had a mandate } \\
\text { for transforming them to } \\
\text { consumers. }\end{array}$ & $\begin{array}{l}\text { Larger pool of consumers and } \\
\text { management has mandate of } \\
\text { satisfaction of each through } \\
\text { products and services. }\end{array}$ \\
\hline 2. Complexity & $\begin{array}{l}\text { Appropriate customization } \\
\text { (accuracy \& applicability) according } \\
\text { to the user. }\end{array}$ & $\begin{array}{l}\text { Facing situations that had not } \\
\text { been documented and system } \\
\text { had not been trained for the } \\
\text { same. }\end{array}$ \\
\hline $\begin{array}{l}\text { 3. Perceived } \\
\text { consequences }\end{array}$ & Increase return on investment & $\begin{array}{l}\text { Enhanced consumer } \\
\text { experiences }\end{array}$ \\
\hline $\begin{array}{l}\text { 4. Affect towards } \\
\text { use }\end{array}$ & $\begin{array}{l}\text { Mass customization; Happy } \\
\text { customers. }\end{array}$ & $\begin{array}{l}\text { Loyalty of the consumers } \\
\text { towards the organization may } \\
\text { increase due to enhanced } \\
\text { consumer experience. }\end{array}$ \\
\hline 5. Social factors & $\begin{array}{l}\text { Internal and external stakeholders } \\
\text { ignore personalized } \\
\text { recommendations given by Al } \\
\text { algorithms. }\end{array}$ & $\begin{array}{l}\text { Consumers do not appreciate } \\
\text { the handling of queries by } \mathrm{Al} \\
\text { machine rather than an } \\
\text { employee (human) }\end{array}$ \\
\hline $\begin{array}{l}\text { 6. Facilitating } \\
\text { conditions }\end{array}$ & Reports on previous trends & Training data set availability \\
\hline
\end{tabular}

Johnsen, Voigt and Corbett (2019) had highlighted behavioural aspects enhances supply chain performance (Johnsen et al., 2019). Maldonado, González-Ramírez, Quijada and Ramírez-Nafarrate (2019) had purposed a decision support system for container stacking operations. Hu and Sheng (2014) had proposed multi-objective real-time scheduling model for reducing empty load ratios. Gallien, Mersereau, Garro, Mora and Vidal (2015) had suggested use of Al for dynamic optimization of stock allocation at different sites. Zhang, Berenguer and Shen (2015) had proposed conic quadratic program for solving reverse logistics in operation management. Tierney, Áskelsdóttir, Jensen and Pisinger (2015) had proposed graph algorithms for shipping fleet repositioning problem. In summary, literature indicates $\mathrm{Al}$ algorithms had been used for different applications in upstream and downstream supply chains. Therefore, authors had suggested Al algorithms can be used in upstream and downstream supply chains for delivering value, as indicated in proposition $4 \mathrm{a}$ and proposition $4 \mathrm{~b}$.

Proposition 4a: Usage of Al algorithms in upstream supply chain in real time increases the horizon of the employee and facilitate the human judgement.

Literature indicates there are many situations in which Al algorithm is required in upstream supply chain, mostly these algorithms are applied for minimizing the budget cost (Job fit). Organizations which are using these had witnessed reduction in procurement costs (Perceived consequences) and had also witnessed effective utilisation of resources (Affect towards use). A symbiosis working relationship is needed 
between the $\mathrm{Al}$ algorithm and employees when working in upstream supply chain. Difficulty is often faced in understanding and implementing the outcomes of the algorithms as such algorithms operate as a black box and traceability of outcome becomes difficult (Social factors).

Proposition 4b: Usage of Al algorithms in downstream supply chain in real time increases the probability of reaching the customers and facilitate in gathering the customers need.

Al can be applied in downstream supply chain when organization don't know who are their target audience are and how to reach them, especially in launching new products and services (Job fit). Application of $\mathrm{Al}$ in downstream supply chain helps in gathering requirements from potential customers (Affect towards use). Employee rigidity is the biggest hindrance in application of Al in downstream supply chain, as customer may compare previous service encounters with current service encounters along with that of social peers (Social factors). Customers may turn towards other customers for support during challenges they may be facing in adapting to the technological change.

Table 5. Proposition 4a and Proposition 4b discussion on Al utilization factors

\begin{tabular}{|c|c|c|}
\hline $\begin{array}{l}\text { Al utilization factor in an } \\
\text { organization }\end{array}$ & Proposition 4a & Proposition 4b \\
\hline 1. Job fit & $\begin{array}{l}\text { Budget optimization problems such } \\
\text { as container stacking, scheduling, } \\
\text { repositioning and many more. }\end{array}$ & $\begin{array}{l}\text { Launching new products and } \\
\text { services. }\end{array}$ \\
\hline 2. Complexity & $\begin{array}{l}\text { Finding the best solution among all } \\
\text { solution, the problem encounter in } \\
\text { these cases is of maximization or } \\
\text { minimization problems }\end{array}$ & $\begin{array}{l}\text { Using appropriate algorithm } \\
\text { for implementation. }\end{array}$ \\
\hline $\begin{array}{l}\text { 3. Perceived } \\
\text { consequences }\end{array}$ & Reduces procurement costs. & Increased profits. \\
\hline $\begin{array}{l}\text { 4. Affect towards } \\
\text { use }\end{array}$ & $\begin{array}{l}\text { Effective utilisation of resources, } \\
\text { experiences in service encounters. }\end{array}$ & $\begin{array}{l}\text { Experience elicitation from } \\
\text { potential customers }\end{array}$ \\
\hline 5. Social factors & $\begin{array}{l}\text { A symbiosis working relationship is } \\
\text { needed between the algorithm and } \\
\text { employees. Difficulty is faced in } \\
\text { understanding and implementing } \\
\text { the outcomes of the algorithms. }\end{array}$ & $\begin{array}{l}\text { Rigidity in changing the } \\
\text { continuous processes. }\end{array}$ \\
\hline $\begin{array}{l}\text { 6. Facilitating } \\
\text { conditions }\end{array}$ & $\begin{array}{l}\text { Digital traces of the previous } \\
\text { operations in an organization. }\end{array}$ & $\begin{array}{l}\text { Customer support systems or } \\
\text { even supporting ecosystems } \\
\text { or platforms. }\end{array}$ \\
\hline
\end{tabular}

\subsection{Insights from social media analytics}

This section presents the insights from social media. Table 6 presents social media analytics method used for extracting the insights on Al utilization factor. Job fit had been mapped to positive tweets tweeted by the experts. Complexity had been mapped to negative tweets tweeted by the 
experts on Twitter. Al utilization factor affect towards use had been mapped to emotion analysis. Social perception on propositions had been demonstrated using word cloud. Perceived consequences and facilitating conditions had been extracted through clustering algorithm.

Table 6. Al utilization factors mapping to social media analytics

\begin{tabular}{|l|l|}
\hline \multicolumn{1}{|c|}{$\begin{array}{c}\text { Al Utilization } \\
\text { Factors }\end{array}$} & \multicolumn{1}{c|}{ Social media analytics Method } \\
\hline 1. Job-fit & $\begin{array}{l}\text { Polarity analysis had been applied on the tweets. Tweets containing positive } \\
\text { opinion have been considered for identifying that how using Al technology will } \\
\text { enhance their job performance. }\end{array}$ \\
\hline 2. Complexity & $\begin{array}{l}\text { Polarity analysis has been applied on the tweets. Tweets containing negative } \\
\text { opinion have been considered as having showcased difficulty in understanding } \\
\text { and using Al in different use cases. }\end{array}$ \\
\hline $\begin{array}{l}\text { 3. Perceived } \\
\text { consequences }\end{array}$ & $\begin{array}{l}\text { Clusters of words occurring together had been used for identifying the choices } \\
\text { made by the organizations for Al adoption for maximum rewards. }\end{array}$ \\
\hline towards use & $\begin{array}{l}\text { Emotion analysis has applied on the tweets, for measuring the feeling of the } \\
\text { workers, professionals, corporates, organizations and others towards the Al } \\
\text { implementation and usage. }\end{array}$ \\
\hline 5. Social factors & $\begin{array}{l}\text { Al perception among other players and market competitors had been presented } \\
\text { using word cloud. }\end{array}$ \\
\hline $\begin{array}{l}\text { 6. Facilitating } \\
\text { conditions }\end{array}$ & $\begin{array}{l}\text { Clusters of words occurring together had been used for identifying the } \\
\text { facilitating conditions of Al mention on social media. }\end{array}$ \\
\hline
\end{tabular}

For extracting the tweets on proposition $1 \mathrm{a}$ and Proposition $1 \mathrm{~b}$, tweets containing the term inspection, quality and defect had been extracted. There were very less tweets containing these terms. Therefore appropriated indicators of the tweets cannot be extracted from social media. But some cases had been extracted for each propositions.

Proposition 1a: Al usage for product inspection enhances product quality as compared to human inspection.

Experts were discussing on Twitter that $\mathrm{Al}$ is helping them in creating visual inspection solution for manufacturing. Organizations (@lsscctv) on Twitter were promoting their under vehicle surveillance system for visual inspection. Usage of service robots had been well discussed on Twitter. One of the popular use case discussed on Twitter is of magnetic climbing robots for steel structures inspection. Other use case is Al powered drone navigation for wind turbine inspection. Experts on Twitter were highlighting Al powered drone and google street view can help in remote inspection.

Proposition 1b: Implementing Al algorithms as the quality function deployment reduces defect rates.

Exact use cases which talks about how Al can be used as quality function deployment was not available on Twitter. However uses cases were discussed how Al is crucial in lowering fleet 
maintenance costs and Al based software such as XRC and NDT Software creates professional quality inspection reports.

For extracting the tweets on proposition $2 \mathrm{a}$ and proposition $2 \mathrm{~b}$, tweets containing the terms ERP, enterprise resource planning, innovation, core capability, product development, multi- agent, distributed, product design, autonomous and self-learning had been extracted. The insights on Al utilization factors, job-fit, complexity, affect towards on proposition $2 \mathrm{a}$ and proposition $2 \mathrm{~b}$ is presented in figure 3. Al utilization factor social perception had been presented in figure 4(a) and insights on Al utilization factors perceived consequences and facilitating had been extracted from word clusters presented in figure 5.

Proposition 2a: Automating the Al algorithm execution on ERP system enables innovation by identifying the core capabilities of the organizations on real time basis for product development.

Proposition 2b: Using multi- agent distributed agents with Al algorithms in product design facilities the creation of autonomous, self-learning products.

The analysis reveals tweet posted on Twitter has positive opinion of implementing Al algorithm for identifying core capabilities and learning (Job-fit: $94.3 \%$ of tweets were containing positive opinion). Experts also highlighted they are facing problems in Al implementation and at the same time they were also pointing out the hurdle faced are worth the outcomes (Complexity: $11.80 \%$ of tweets were containing negative opinion). The emotional analysis, result reveals experts are having mix feeling towards the Al implementation some are happy (17.14\% of the tweets on proposition $2 \mathrm{a}$ and $2 \mathrm{~b}$ were on expressing joy), some are in fear what will Al will do ( $15.25 \%$ of the tweets on proposition $2 \mathrm{a}$ and $2 \mathrm{~b}$ were on expressing fear), some are trusting Al technologies as well (34.63\% of the tweets on proposition $2 \mathrm{a}$ and $2 \mathrm{~b}$ were on expressing trust) and some posted use cases of anticipation (21.04\% tweets) of what Al can achieve in the future.

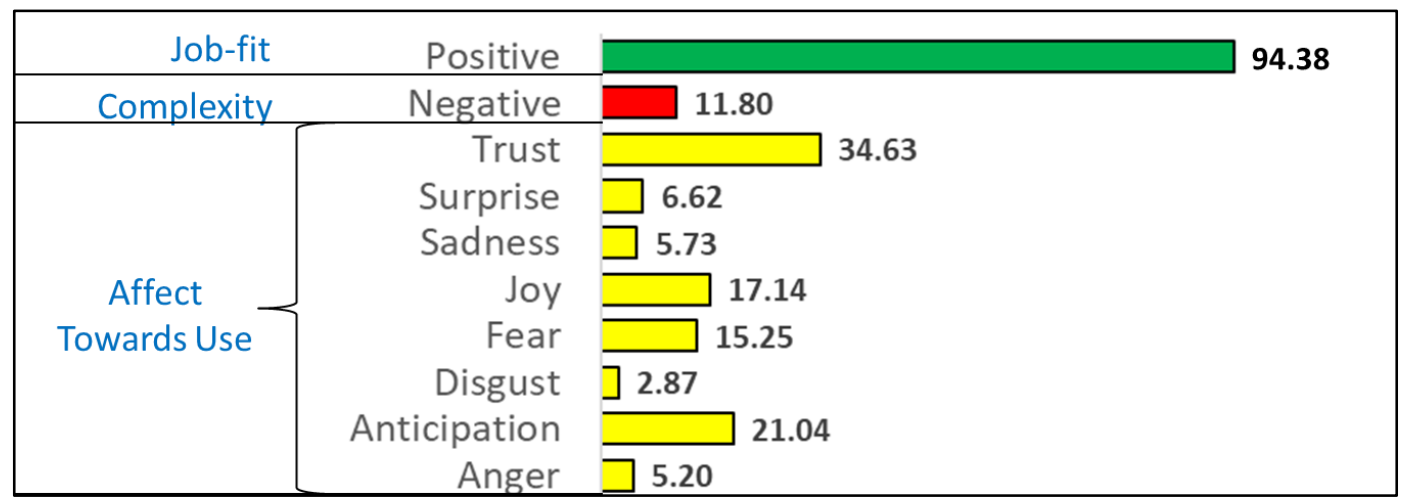

Figure 3. Presents indicators on Al utilization factors, job-fit, complexity and affect towards use for Proposition 2a and Proposition 2b

The figure 4(a) reveals using Al for enterprise planning and learning will lead the organization towards hyper productivity and will make the organisation as "smart company" (social factors). With the help of the Al implementation companies can built in "cognitive automation" and "intelligent automation". Figure 5 reveals perceived consequences of Al implementation on 
enterprise resource planning to innovation, digital business such as autonomous vehicle, service robots and many more. Al adoption by the ecosystem will be facilitated by the implementation of other related technologies such as big data, internet of things and machine learning algorithms.
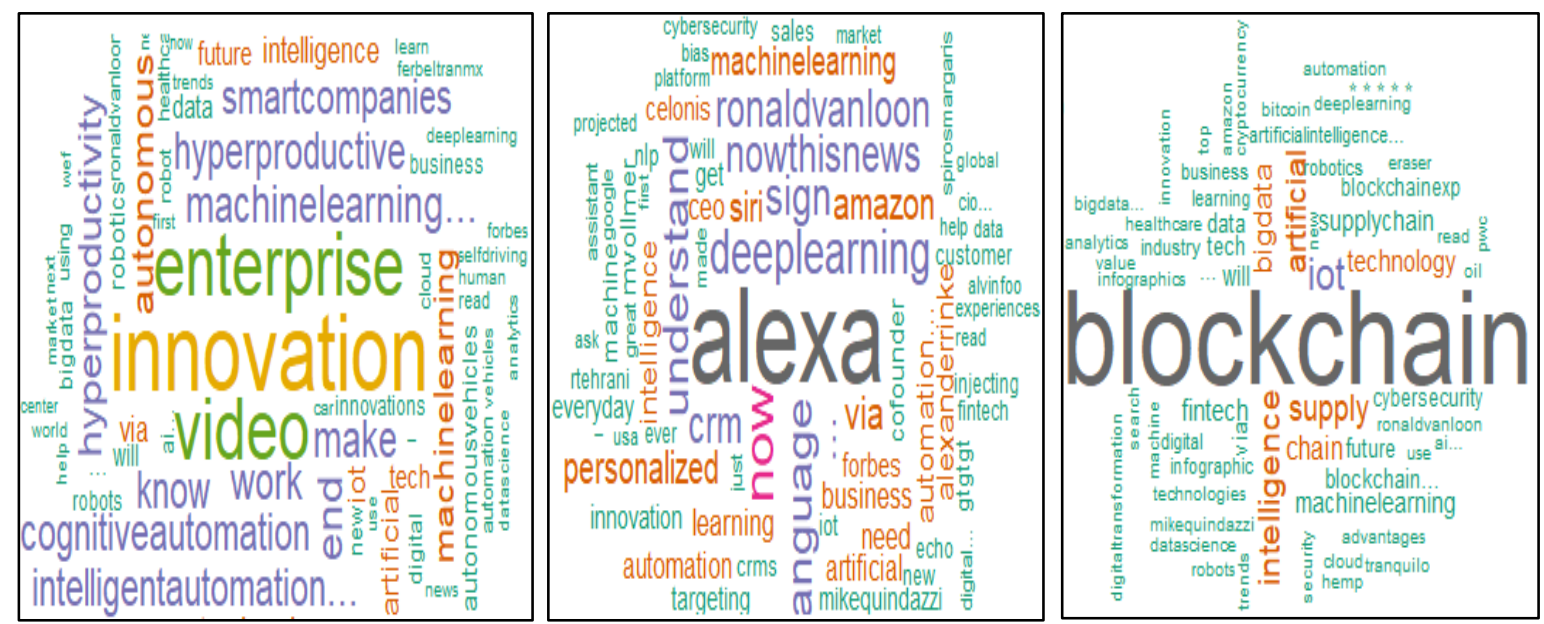

Figure 4. (a) Social perception on proposition 2a and 2b; (b) Social perception on proposition 3a and 3b; (c) Social perception on proposition $4 a$ and $4 b$;

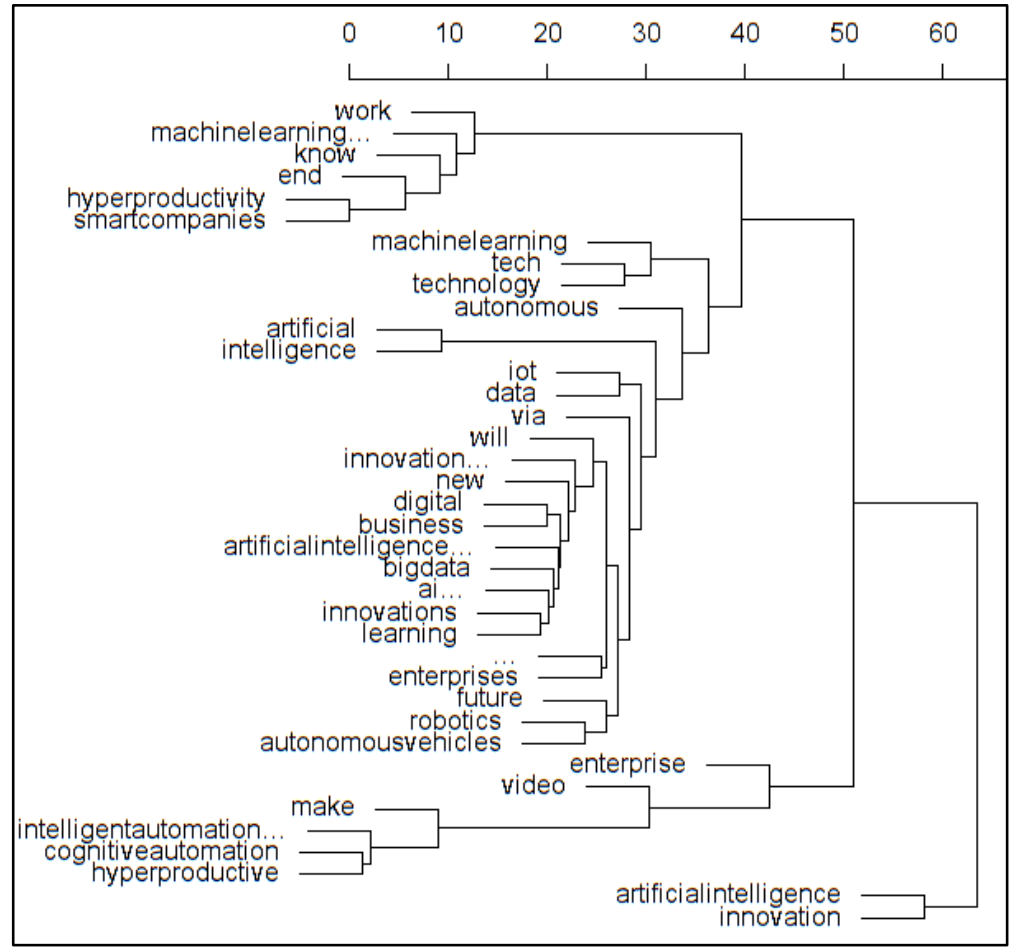

Figure 5. Clustering of the words from tweets posted on proposition $2 a$ and $2 b$ for getting insights on perceived consequences and facilitating condition

For extracting the tweets on proposition $3 \mathrm{a}$ and proposition $3 \mathrm{~b}$, tweets containing the terms recommender, personalized, targeting, advertisement, return on investment, Alexa, Siri, CRM, customer relationship management and customer experiences had been extracted. The insights on Al utilization factors, job-fit, complexity, affect towards on proposition 3a and proposition $3 \mathrm{~b}$ is presented in figure 6. 
Al utilization factor social perception had been presented in figure $4(\mathrm{~b})$ and insights on Al utilization factors perceived consequences and facilitating condition had been extracted from word clusters presented in figure 7.

Proposition 3a: Using inbuilt recommender systems (by Al algorithm) for personalized targeting of digital advertisement can increase return on investment.

Proposition 3b: Using Al systems like chatbots for customer relationship management enhances customer experiences as compared to human engagement.

The analysis reveals tweet posted on Twitter has moderate opinion of implementing Al algorithms like chatbots on customer relationship management (Job-fit: $67.81 \%$ of tweets were containing positive opinion). Experts were also pointing out they are facing problems in Al implementation may the ethical and legal issues in extracting knowledge from customer personal data (Complexity: $14.22 \%$ of tweets were containing negative opinion). The results of emotional analysis reveals experts having lots of fear in $\mathrm{Al}$ implementation in this area $(18.33 \%$ and $17.45 \%$ of the tweets on proposition $3 \mathrm{a}$ and $3 \mathrm{~b}$ were on expressing fear and anticipation, respectively). The sample also had marked $31.47 \%$ of the trust tweets, also.

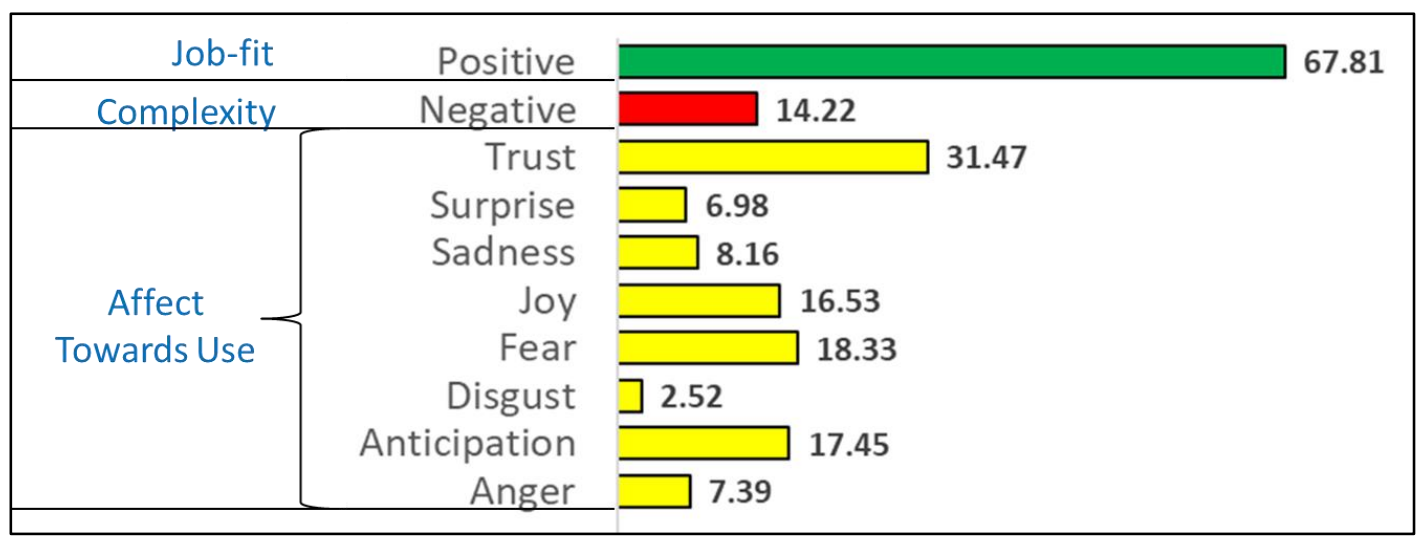

Figure 6. Presents indicators on Al utilization factors job-fit, complexity and affect towards use for Proposition 3a and Proposition 3b

The figure 4(b) reveals companies such as Amazon, Forbes and other individual influencers such as ronaldvaloon, alexanderrinke, mikequindazzi are posting a lot on the usage of Al for customer relationship management. However they are holding mixed opinion on the use of Al powered system for customer management and its impacts. Usage of Al will help companies offer personalized services to their customers (perceived consequences). Deep learning and natural language processing will help Al implementation for proposition $3 a$ and $3 b$. However customers may not like the services due to cultural differences which the system may not be able to differentiate much. 


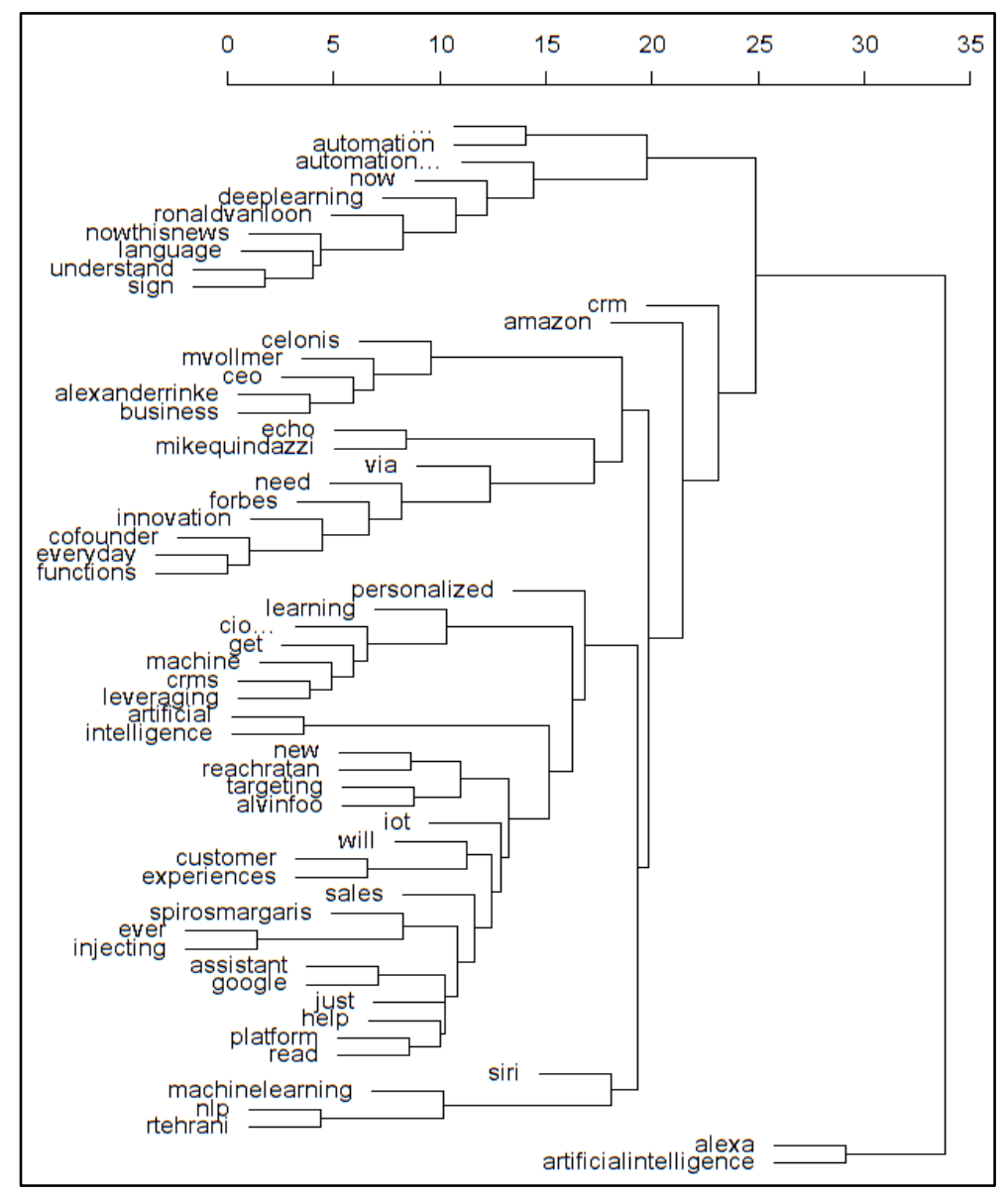

Figure 7. Clustering of the words from tweets posted on proposition $3 \mathrm{a}$ and $3 \mathrm{~b}$ for getting insights on perceived consequences and facilitating condition

For extracting the tweets on proposition $4 \mathrm{a}$ and proposition $4 \mathrm{~b}$, tweets containing the terms supply chain had been extracted. The insights on Al utilization factors, job-fit, complexity, affect towards on proposition $4 \mathrm{a}$ and proposition $4 \mathrm{~b}$ is presented in figure 8 . Al utilization factor social perception had been presented in figure $4(\mathrm{c})$ and insights on Al utilization factors perceived consequences and facilitating condition had been extracted from word clusters presented in figure 9.

Proposition 4a: Usage of artificial intelligence algorithm in upstream supply chain in real time increases the horizon of the employee and facilitate the human judgement.

Proposition 4b: Usage of artificial intelligence algorithm in downstream supply chain in real time increases the probability of reaching the customers and facilitate in gathering the customers need.

The analysis reveals tweet posted on Twitter has positive opinion of implementing Al algorithm in upstream and downstream supply chain (Job-fit: $92.24 \%$ of tweets were containing positive opinion). Experts were also pointing out they were facing problems in Al implementation slightly more than other cases (Complexity: $14.53 \%$ of tweets were containing negative opinion). The analysis of emotions reveals experts are having trust in Al technology, highest among all the cases (45.76\% of the tweets on proposition $4 \mathrm{a}$ and $4 \mathrm{~b}$ were on expressing trust), and experts are happy on Al implementation in supply chain area 
(27.26\% of the tweets on proposition $4 \mathrm{a}$ and $4 \mathrm{~b}$ were on expressing joy; $21.97 \%$ of the tweets on proposition $4 \mathrm{a}$ and $4 \mathrm{~b}$ were on expressing fear).

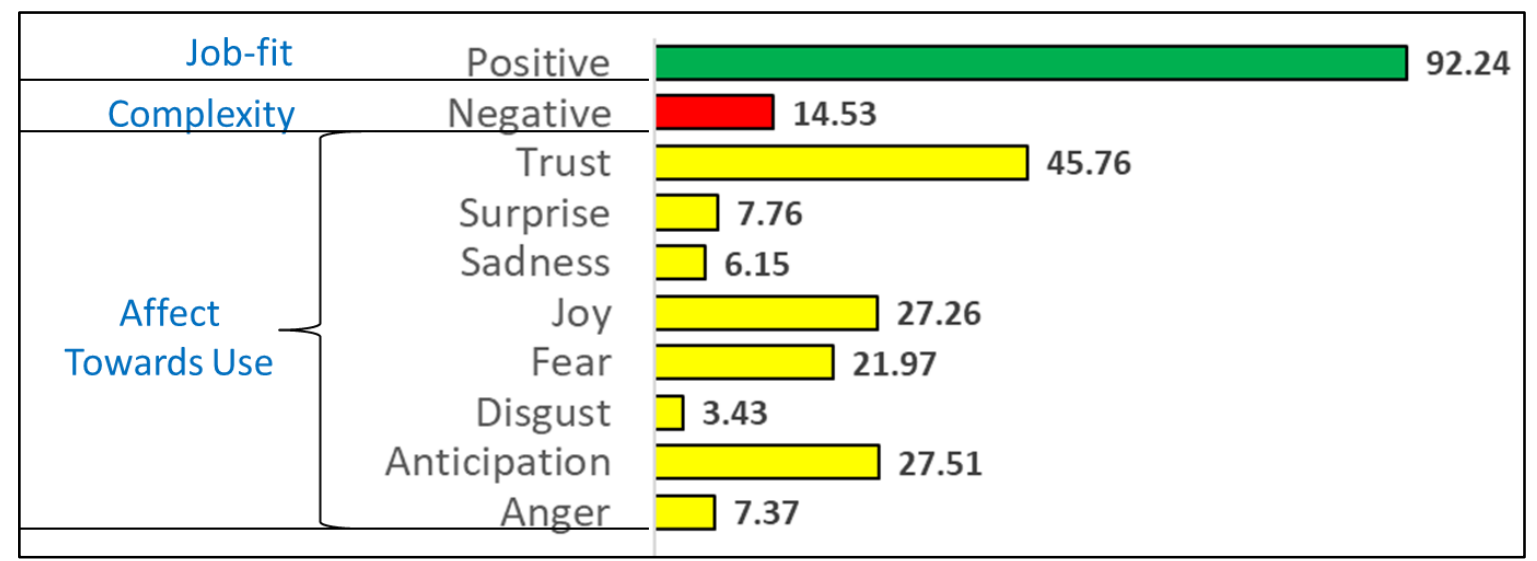

Figure 8. Presents indicators on Al utilization factors, job-fit, complexity and affect towards use for Proposition 4a and Proposition 4b

The figure 4(c) reveals companies such as PWC and other personality such as ronaldvaloon, mikequindazzi are posting highly on proposition $4 \mathrm{a}$ and proposition $4 \mathrm{~b}$. The figure 9 reveals using Al for upstream and downstream supply chain digital transformation within an organisation can be promoted (social factors). Some the sectors were this can used are healthcare, cyber security, fintech, info graphics and many more. The blockchain technology can augment the implementation of $\mathrm{Al}$ in supply chain.

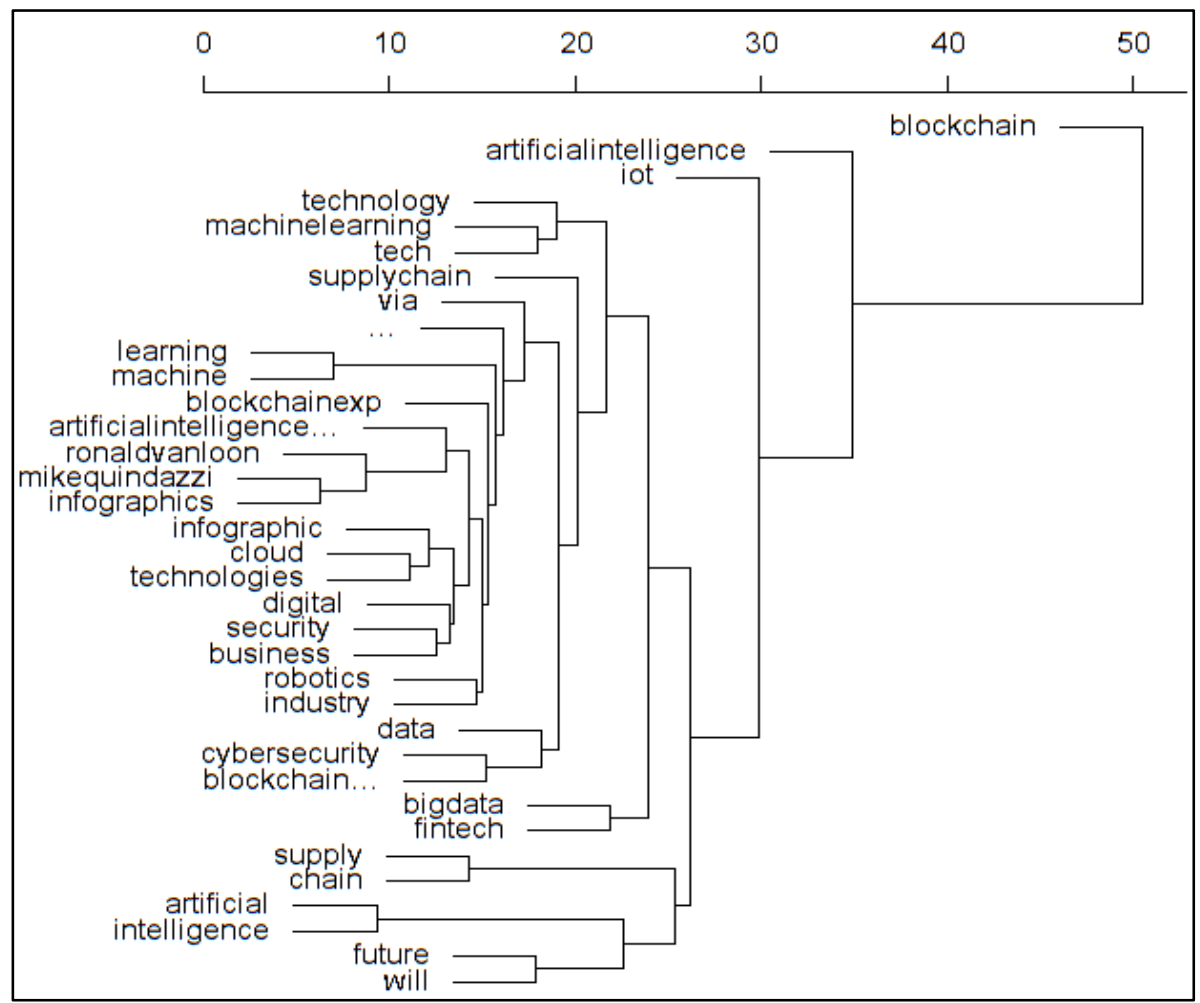

Figure 9. Clustering of the words from tweets posted on proposition $4 \mathrm{a}$ and $4 \mathrm{~b}$ for getting insights on perceived consequences and facilitating condition 


\section{Discussion}

This article explores the utilization of the $\mathrm{Al}$ in different elements of the $\mathrm{OM}$, manufacturing, product development, services and supply chain through academic literature and expert (workers, professionals, corporates \& organizations) opinion on Twitter. Through the study, authors attempted to expand the knowledge of managers and organization on Al utilization within an enterprise by combining academic literature and practice driven discussions in social media.

A systematic literature review has been undertaken in academic literature to address the propositions developed for our study. The though behind undertaking the systematic literature review is that it will capture the state of literature that is well developed and established with fair degree of accuracy at the cost of recency. To address recency, data collection has been done in Twitter where extraction step in Twitter is followed by data pre-processing step. The pre-processing sub-steps includes data transformation, storing of data, data reduction and data cleaning. For data analysis, descriptive analysis and text analytics had been used. Descriptive analysis provides the first level insights into the data by applying the simple functions such as count, sum, mean, median and mode. Text analytics extracts information from textual data. The collective complementary intelligence of different stakeholders, namely academia and practitioners, have been used in this study to build and validate propositions by taking inputs from complementary sources and validating them through an triangulation like approach, conceptual, practical and innovation.

Now we attempt to summarize the insights extracted from academic literature and social media analytics on proposition 1a, 1b, 2a, 2b, 3a, 3b, 4a and 4b. Al utilization factors had been framed by getting inspiration from model of PC utilization (Thompson et al., 1991) constructs, job-fit, complexity, long-term consequences, affect towards use, social factors and facilitating conditions.

For proposition 1a academic literature gives a positive signal on usage of Al for big size product inspection. Usage of Al will enhance the product quality. Academic literature indicates usage of Al as quality deployment function will be beneficial for large scale production. Especially when humans get exhausted, then Al powered system will play a great role in maintaining product quality standards, which is in line with literature which indicates $\mathrm{Al}$ usage for inspection reduces cost and time spent on the inspection (Librantz et al., 2017). On social media experts were discussing on service robots and Al powered drone usage for inspecting steel structures and wind turbine respectively. For proposition $1 \mathrm{~b}$ exact use cases were not available but there were tweets in which usage of software's XRC and NDT had been discussed for creating professional inspection reports.

Academic literature indicates Al implementation on ERP is best suited for MNCs working across the world, which may lead to minimization of resources and improving overall productivity (Vickranth et al., 2019). The biggest hurdle in implementation is selection of data sources or to apply on which databases or data warehouses maintained by organizations. Explainability of difference of outcome to internal employees may also be a challenge. Another hurdle in implementation is that Al algorithms for big data, characterized by high volume, variety, veracity and velocity, have to demonstrate maturity (Shi and Wang, 2019). On social media, experts have positive opinion on Al algorithm usage for learning and identifying core capabilities of an organization. Some experts had highlighted Al utilization with an organization will make 
the organization "smart" as well as hyper productive. This will subsequently will help the organization in developing digital business and innovation.

Literature indicates Al implementation for internal and external stakeholders is ideal for those mature organization who really wants to capture the large segments of the market. Appropriate suggestion by the Al algorithm for each customer is the challenging job for the recommender system. Academic literature contains positive as well as negative examples for using Al powered system for customer relationship management. On Twitter, experts did not have significant differences among positive and negative opinion regarding the use of Al for connecting with external or internal stakeholders. Experts on Twitter had indicated natural language processing and deep learning will facilitates the Al implementation for enhancing customer experiences (Kumar et al., 2019; Overgoor et al., 2019; Wang et al., 2019).

Literature indicates implementation for upstream supply chain will be demanding in the situations where budget is under consideration. Al implementation will lead to reduction in procurement costs by providing employees with diverse and different options (Metcalf et al., 2019). For downstream supply chain, Al implementation may be favourable when organizations are launching new products. Al will help the organizations in elicitation of requirements and as well as predicting what will be costumer's preference among requirements in future and may help in new product development. Employee and customer rigidity is the biggest hindrance in $\mathrm{Al}$ implementation in bth upstream and downstream activities, which is in line with Berlak, Hafner and Kuppelwieser (2020) finding. Experts on Twitter holds positive opinion on implementing $\mathrm{Al}$ in upstream and downstream supply chain management within an enterprise. They reveal that such an Al implementation within supply chain can be augmented through the use of blockchain.

\subsection{Implication for practice}

In today's age of artificial intelligence, authors of the study supports Shrestha, Ben-Menahem and von Krogh (2019) argument that decision making within organizations can be sequential (Al-to-human and human-to-Al) or decision making within organizations can be aggregated between humans and machines. In some situation's humans can fully be depended on Al for decision making purposes. Al utilization in OM can increase organization efficiency, return on investment, quality, innovation, customer satisfaction, employee empowerment and many more.

On the basis of the insights from academic literature and social media analytics Figure 10 proposes the value chain model for $\mathrm{Al}$ implementation in OM. Firm infrastructure plays a key role in Al implementation. Adoption of Al highly depends on the employee's attitude towards the technology (Berlak et al., 2020). Literature indicates and authors also feel the implementation will be facilitated by highly educated and smart employees (Morikawa, 2017). The key decisions which needs to be taken by organization for Al implementation are: selection of data sources; selection of algorithms; and the training and deployment of these systems with an organization. The success of Al powered systems lies on the symbiosis relationship between employees and Al machine. 


\section{Firm Infrastructure}

\section{Artificial Intelligence Adoption \& Infusion}

\begin{tabular}{|c|c|c|c|}
\hline Manufacturing & Product Development & Services & Supply Chain \\
\hline $\begin{array}{l}\text { - Product inspection } \\
\text { - Quality function } \\
\text { deployment }\end{array}$ & $\begin{array}{l}\text { - Identifying core capabilities } \\
\text { - Multi - agent distributed } \\
\text { - Autonowledge systems } \\
\text { products }\end{array}$ & $\begin{array}{l}\text { - } \text { Recommender } \\
\text { system } \\
\text { - Customer } \\
\text { relationship } \\
\text { management } \\
\text { - Personalized } \\
\text { targeting for ads }\end{array}$ & $\begin{array}{l}\text { - Upstream supply } \\
\text { chain } \\
\text { - Downstream } \\
\text { supply chain }\end{array}$ \\
\hline
\end{tabular}

Data: Number, text, images, audio \& video
Algorithms: neural network, deep learning, speech algorithms etc.
Implementations, Modifications and Up gradations: Training, testing and deploying

\section{Responsiveness of Employees towards the System}

Figure 10. Value chain model Artificial Intelligence implementation in Operation Management

Figure 11 proposes the roadmap for Al adoption in OM within an organization. Step 1 would be to identify the applications of OM in which Al can be applied. Some of such applications had been illustrated and explored, manufacturing element of OM for product inspection and quality function deployment in proposition 1a and proposition $1 \mathrm{~b}$ respectively. Product development element of OM for identifying core capabilities and self-learning products is highlighted in proposition $2 \mathrm{a}$ and proposition $2 \mathrm{~b}$ respectively. Further services elements of OM for personalized targeting and enhancing customer experiences are highlighted in proposition $3 \mathrm{a}$ and proposition $3 \mathrm{~b}$ respectively. Lastly supply chain elements of OM for facilitating employee judgement and gathering customers need in proposition $4 \mathrm{a}$ and proposition $4 \mathrm{~b}$.

Step 2, check the feasibility of the application implementation on Al utilization constructs, job-fit, complexity, long-term consequences, affect towards use, social factors and facilitating conditions. The organisations which had undertaken digital transformation within their organization for those checking the feasibility and implementation of Al powered system will be on the lighter side. The organisations can also list the perceived usefulness and perceived ease of use of the application.

Step 3, train and implement Al algorithm, by identifying the attributes and algorithms (i.e., neural network, deep learning, speech algorithms, object recognition algorithms, maximum likelihood, uniform cost search and many more). During a complex situation professionals, corporates, organizations and data workers can use data which had been made available due to the digital initiative undertaken by the organizations. Al system can use this data for learning, training, reasoning and updating the systems (Jarrahi, 2018).

Step 4, educate the employees to be responsive enough to the alertness, notification, suggestions provided by the Al algorithms. Such implementation of Al will have technology upgradation, and the users need to be trained about the outcome of the new technology. In particular, the black box nature of the outcome requires sensitization among stakeholders. Managerial interventions may be required to address 
fairness, explainability and accountability of the outcomes to the stakeholders and exclusive training to address this need may be useful for employees.

Step 5, check the validity and reliability of the OM system with Al implementation from time to time. Identify the features which can improve the efficiency of the Al system, if any. Cultural sensitivity would be key for future success of adoption among stakeholders, especially while engaging with external stakeholders of the firm like supplier networks and customer networks. If possible Al powered systems should be have self-organisation capability. Step 6, is a continuous cycle which is required for upgrading the system as per market needs.

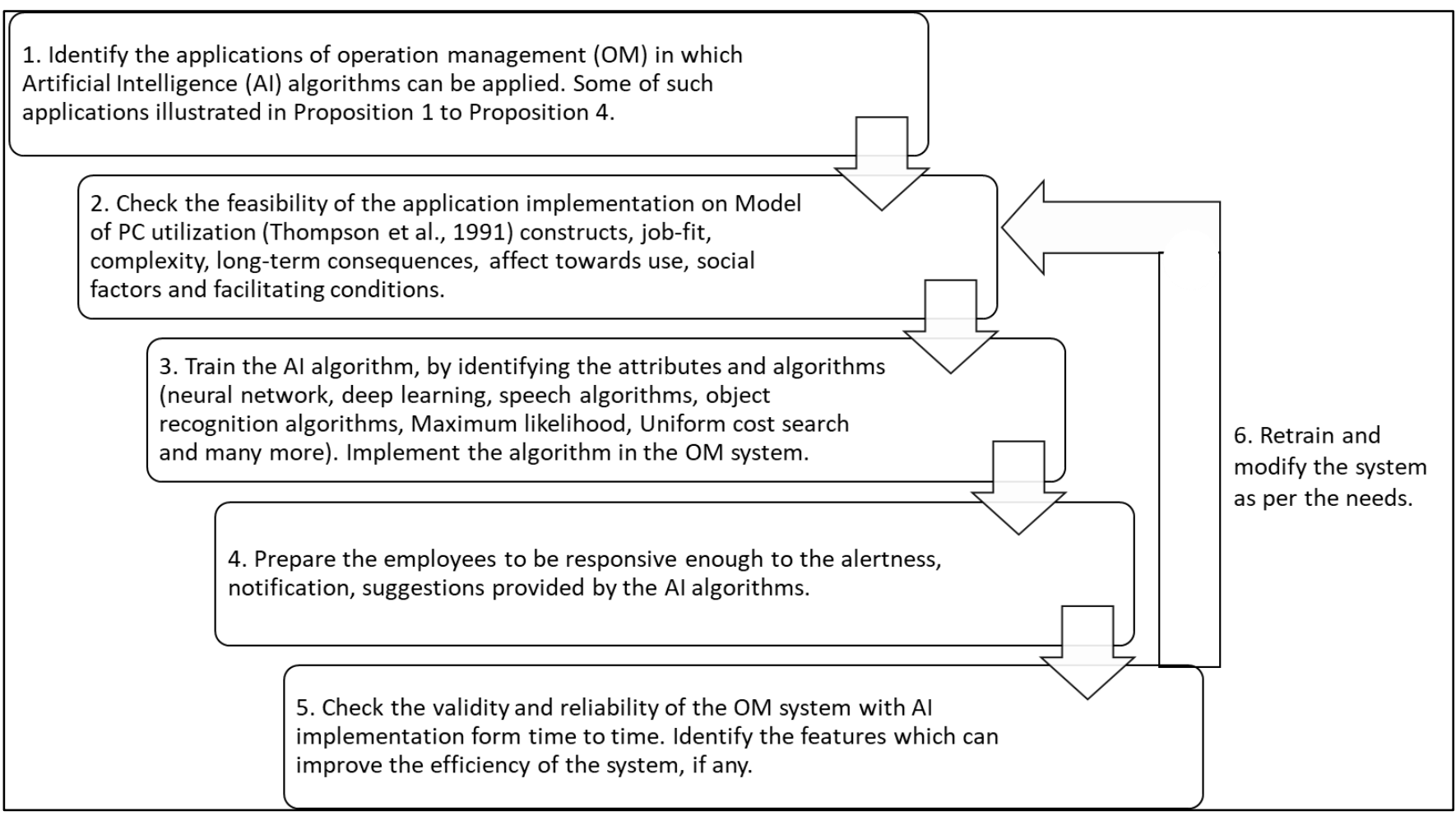

Figure 11. Roadmap for artificial intelligence adoption in operation management

\subsection{Implications for research}

The current article focus on providing the insights to the managers on how to use Al in different components of $\mathrm{OM}$, first research gap identified for the study. For this different use-cases in different component of OM such as product inspection, quality function deployment, identifying core capabilities, product designing, recommender systems, customer relationship management, upstream and downstream supply chain had been discussed on utilization factors, i.e, job fit, complexity, perceived consequences, affect towards use, social factors and facilitating conditions. The practical implementation of the use cases may face some technical, ethical and social issues. Therefore authors would like to suggest the future scholars to take any of the eight propositions and try to do in-depth study of the implementation within the organization frame.

Gunasekaran and Ngai (2012) had highlighted there is a need to develop OM models for converting information into knowledge, therefore on the basis of the study insights, authors had proposed roadmap for Al powered system adoption in OM, figure 11. Future scholars can study how this roadmap will be adopted by the organisations under different scenarios such as recession, overload and many more. The study can also be 
repeated for other industries domains and subsequently the usage of Al powered system will differ from one industry segment to others.

The article tries to answer the question highlighted by Haenlein and Kaplan (2019): how people and Al supported systems can coexist with each other. During uncertain situations arising out of adoption of this disruptive technology; professionals, corporates, organizations and data workers can make swift intuitive decisions. This will be further augmented as Al systems can provide access to real time information and prediction for near future. Professionals, corporates and organizations can negotiate and build consensus among stakeholders whereas $\mathrm{Al}$ can present diverse perspectives of different scenarios. Authors of the article supports the argument that $\mathrm{Al}$ powered system and human should have synergy and should have a symbiotic relationship. It will be interesting if others authors can also explore this question from different perspective of the current article.

\section{Conclusion}

This article tries to explore the research question how Al can be utilized in OM in organizations through the complementary analysis of academic literature and social media data. By doing so, the complementary perspectives of academic experts along with practice experts have been analysed and documented. In this article; eight propositions on Al utilization in different element of OM had been explored. Results indicates Al utilization in OM will help organizations in increasing organization efficiency, return on investment, quality, innovation, customer satisfaction and employee empowerment. Initially organization will face lot of difficulty in Al implementation in an organization for making it easier the articles proposes the roadmap for Al Adoption in OM. Authors feel employees and Al powered system should work symbiotically, as both are depending on each other and success of Al systems lies in the mutual understanding of both. Authors also agree with other scholars that Al will become a core dominant infrastructure among technologies in future as internet is today (Haenlein and Kaaplan, 2019). Al powered system will support decision makers in an organization across all functions.

Table 7 summarizes the indications on propositions from academic literature and social media analytics. Proposition $1 \mathrm{a}$ and proposition $1 \mathrm{~b}$ had been given positive indication by academic literature for big size products and large-scale production respectively. No indication had been given on proposition 1a and $1 \mathrm{~b}$ by experts discussing on social media. Both academic literature and expert on social media gives positive indication for proposition $2 \mathrm{a}$. For proposition $2 \mathrm{~b}$ no indication had been given in academic literature but expert on social media is positive about implementation. For proposition $3 a$ and proposition $3 \mathrm{~b}$ literature gives positive indication and suggests its implementation for converting larger pool of potential customers to consumers for specific products. Social media analytics indicates neutral opinion on proposition $3 \mathrm{a}$ and proposition $3 \mathrm{~b}$ implementation. Both literature and social media indicates positive on proposition $4 a$ and proposition $4 b$.

Table 7. Indication on proposition form academic literature and social media analytics

\begin{tabular}{|l|l|l|}
\hline \multicolumn{1}{|c|}{ Proposition } & Academic literature indication & \multicolumn{1}{|c|}{ Social media indication } \\
\hline Proposition 1a & Positive, for large products & $\begin{array}{l}\text { No indication due to less tweets } \\
\text { on particular proposition }\end{array}$ \\
\hline Proposition 1b & $\begin{array}{l}\text { Positive, for large scale } \\
\text { production processes }\end{array}$ & $\begin{array}{l}\text { No indication due to less tweets } \\
\text { on particular proposition }\end{array}$ \\
\hline
\end{tabular}




\begin{tabular}{|l|l|l|}
\hline Proposition 2a & $\begin{array}{l}\text { Positive, ERPs in MNC allows } \\
\text { operational efficiency to be } \\
\text { achieved }\end{array}$ & $\begin{array}{l}\text { Positive, differences of } \\
\text { outcome to different internal } \\
\text { stakeholder needs intervention }\end{array}$ \\
\hline Proposition 2b & $\begin{array}{l}\text { No significant indication in } \\
\text { exing literature }\end{array}$ & $\begin{array}{l}\text { Positive, customer oriented Al } \\
\text { systems can help in product } \\
\text { evolution }\end{array}$ \\
\hline Proposition 3a & $\begin{array}{l}\text { Positive, can be used for higher } \\
\text { penetration among customer } \\
\text { segments by large MNCs }\end{array}$ & $\begin{array}{l}\text { Neutral opinion due to ethical } \\
\text { and legal constraints of using } \\
\text { customers data }\end{array}$ \\
\hline Proposition 3b & $\begin{array}{l}\text { Positive as operational } \\
\text { experiences and outcome is } \\
\text { more efficiently achieved }\end{array}$ & $\begin{array}{l}\text { Neutral opinion due to } \\
\text { challenges faced from } \\
\text { customer cultural diversity }\end{array}$ \\
\hline Proposition 4a & $\begin{array}{l}\text { Positive, as decision making is } \\
\text { hugely improved in upstream } \\
\text { supply chain. }\end{array}$ & $\begin{array}{l}\text { Positive, however differences } \\
\text { of outcome towards partners } \\
\text { may need interventions }\end{array}$ \\
\hline Proposition 4b & $\begin{array}{l}\text { Positive as customer's needs } \\
\text { are captured better }\end{array}$ & $\begin{array}{l}\text { Positive, but concerns } \\
\text { surrounding information risk } \\
\text { and privacy loss is highlighted. }\end{array}$ \\
\hline
\end{tabular}

\section{Limitation and Future Work}

The current article builds proposition based on analysis of two complementary perspectives arising of different sources of data. Also, our findings are applicable based on limitations of the data sources, namely, we were able to analyse only what has been published. Similar exploration could also be undertaken by looking at survey-based validation of the model by taking inputs from experts. Further our exploration indicates that not much of work has been undertaken in the area of using Al on a real time basis in operations management. Therefore, authors feel the implementation of Al in that field will be fruitful. The articles lack cases on the real time implementation of $\mathrm{Al}$, future scholars can explore the same by taking the learnings of the current article.

\section{References}

Abrahams, A. S., Jiao, J., Wang, G. A., \& Fan, W. (2012). Vehicle defect discovery from social media. Decision Support Systems, 54(1), 87-97.

Al Elish, M. C., \& Boyd, D. (2018). Situating methods in the magic of Big Data and Al. Communication monographs, 85(1), 57-80.

Aligon, J., Gallinucci, E., Golfarelli, M., Marcel, P., \& Rizzi, S. (2015). A collaborative filtering approach for recommending OLAP sessions. Decision Support Systems, 69, 20-30.

Alt, R., Ehmke, J. F., Haux, R., Henke, T., Mattfeld, D. C., Oberweis, A., Paech, B. \& Winter, A. (2019). Towards customer-induced service orchestration-requirements for the next step of customer orientation. Electronic Markets, 29(1), 79-91. 
Arnott, D., Lizama, F., \& Song, Y. (2017). Patterns of business intelligence systems use in organizations. Decision Support Systems, 97, 58-68.

Bader, V., \& Kaiser, S. (2019). Algorithmic decision-making? The user interface and its role for human involvement in decisions supported by artificial intelligence. Organization, 26(5), 655-672.

Banomyong, R., Varadejsatitwong, P., \& Oloruntoba, R. (2019). A systematic review of humanitarian operations, humanitarian logistics and humanitarian supply chain performance literature 2005 to 2016. Annals of Operations Research, 283(1-2), 71-86.

Bauer, J., \& Nanopoulos, A. (2014). Recommender systems based on quantitative implicit customer feedback. Decision Support Systems, 68, 77-88.

Berlak, J., Hafner, S., \& Kuppelwieser, V. G. (2020). Digitalization's impacts on productivity: a model-based approach and evaluation in Germany's building construction industry. Production Planning \& Control. DOI: 10.1080/09537287.2020.1740815

Bhatti, U. A., Huang, M., Wu, D., Zhang, Y., Mehmood, A., \& Han, H. (2019). Recommendation system using feature extraction and pattern recognition in clinical care systems. Enterprise information systems, 13(3), 329-351.

Bordeleau, F. E., Mosconi, E., \& de Santa-Eulalia, L. A. (2020). Business intelligence and analytics value creation in Industry 4.0: a multiple case study in manufacturing medium enterprises. Production Planning \& Control, 31(2-3), 173-185.

Brock, J. K. U., \& Von Wangenheim, F. (2019). Demystifying Al: What Digital Transformation Leaders Can Teach You about Realistic Artificial Intelligence. California Management Review, 61(4), 110-134.

Burton-Jones, A., Akhlaghpour, S., Ayre, S., Barde, P., Staib, A., \& Sullivan, C. (2020). Changing the conversation on evaluating digital transformation in healthcare: Insights from an institutional analysis. Information and Organization, 30(1), 100255.

Carrillo, J. E., Druehl, C., \& Hsuan, J. (2015). Introduction to innovation within and across borders: A review and future directions. Decision Sciences, 46(2), 225-265.

Chae, B. K. (2015). Insights from hashtag \#supplychain and Twitter Analytics: Considering Twitter and Twitter data for supply chain practice and research. International Journal of Production Economics, 165, 247-259.

Chakraborty, A., \& Kar, A. K. (2017). Swarm intelligence: A review of algorithms. In Nature-Inspired Computing and Optimization (pp. 475-494). Springer, Cham.

Davis, F. D. (1989). Perceived Usefulness, Perceived Ease of Use, and User Acceptance of Information Technology. MIS Quarterly, 13(3), 319-340.

Dolnicar, S., \& Ring, A. (2014). Tourism marketing research: Past, present and future. Annals of Tourism Research, 47, 31-47. 
DuHadway, S., Carnovale, S., \& Hazen, B. (2019). Understanding risk management for intentional supply chain disruptions: Risk detection, risk mitigation, and risk recovery. Annals of Operations Research, 283(1), 179-198.

Duan, Y., Edwards, J. S., \& Dwivedi, Y. K. (2019). Artificial intelligence for decision making in the era of Big Data-evolution, challenges and research agenda. International Journal of Information Management, 48, 63-71.

Dubey, R., Gunasekaran, A., Bryde, D. J., Dwivedi, Y. K., \& Papadopoulos, T. (2020). Blockchain technology for enhancing swift-trust, collaboration and resilience within a humanitarian supply chain setting. International Journal of Production Research, 1-18. Dol: https://doi.org/10.1080/00207543.2020.1722860

Dwivedi, Y. K., Hughes, L., Ismagilova, E., Aarts, G., Coombs, C., Crick, T., Duan, Y., Dwivedi, R., Edwards, J., Eirug, A., Galanos, V., Ilavarasan, P. V., Janssen, M., Jones, P., Kar, A. K., Kizgin, H., Kronemann, B., Lal, B., \& Williams, M.D. (2019). Artificial Intelligence (Al): Multidisciplinary perspectives on emerging challenges, opportunities, and agenda for research, practice and policy. International Journal of Information Management, 101994. DOI: 10.1016/j.ijinfomgt.2019.08.002

EIMassah, S., \& Mohieldin, M. (2020). Digital transformation and localizing the Sustainable Development Goals (SDGs). Ecological Economics, 169, 106490.

Erevelles, S., Fukawa, N., \& Swayne, L. (2016). Big Data consumer analytics and the transformation of marketing. Journal of Business Research, 69(2), 897-904.

Eriksson, T., Bigi, A., \& Bonera, M. (2020). Think with me, or think for me? On the future role of artificial intelligence in marketing strategy formulation. The TQM Journal. DOI: 10.1108/TQM-12-2019-0303

Gallien, J., Mersereau, A. J., Garro, A., Mora, A. D., \& Vidal, M. N. (2015). Initial shipment decisions for new products at Zara. Operations Research, 63(2), 269-286.

Grover, P., \& Kar, A. K. (2017). Big data analytics: A review on theoretical contributions and tools used in literature. Global Journal of Flexible Systems Management, 18(3), 203-229.

Grover, P., Kar, A. K., \& Ilavarasan, P. V. (2019b). Impact of corporate social responsibility on reputationInsights from tweets on sustainable development goals by CEOs. International Journal of Information Management, 48, 39-52.

Grover, P., Kar, A. K., \& Janssen, M. (2019). Diffusion of blockchain technology. Journal of Enterprise Information Management, 32(5), 735-757.

Grover, P., Kar, A. K., Dwivedi, Y. K., \& Janssen, M. (2019a). Polarization and acculturation in US Election 2016 outcomes-Can twitter analytics predict changes in voting preferences. Technological Forecasting and Social Change, 145, 438-460.

Gunasekaran, A., \& Ngai, E. W. (2012). The future of operations management: an outlook and analysis. International Journal of Production Economics, 135(2), 687-701.

Gupta, S., Kar, A. K., Baabdullah, A., \& Al-Khowaiter, W. A. (2018). Big data with cognitive computing: A review for the future. International Journal of Information Management, 42, 78-89. 
Haenlein, M., \& Kaplan, A. (2019). A brief history of artificial intelligence: On the past, present, and future of artificial intelligence. California Management Review, 61(4), 5-14.

Hart, C. (1998). Doing a Literature Review: Releasing the Social Science Research Imagination. Sage, Thousand Oaks, CA.

Huang, M. H., Rust, R., \& Maksimovic, V. (2019). The Feeling Economy: Managing in the Next Generation of Artificial Intelligence (AI). California Management Review, 61(4), 43-65.

Huang, T., \& Van Mieghem, J. A. (2014). Clickstream data and inventory management: Model and empirical analysis. Production and Operations Management, 23(3), 333-347.

Hughes, L., Dwivedi, Y. K., Misra, S. K., Rana, N. P., Raghavan, V., \& Akella, V. (2019). Blockchain research, practice and policy: Applications, benefits, limitations, emerging research themes and research agenda. International Journal of Information Management, 49, 114-129.

Ismagilova, E., Hughes, L., Dwivedi, Y. K., \& Raman, K. R. (2019). Smart cities: Advances in research-An information systems perspective. International Journal of Information Management, 47, 88-100.

Jarrahi, M. H. (2018). Artificial intelligence and the future of work: human-Al symbiosis in organizational decision making. Business Horizons, 61(4), 577-586.

Johnsen, L. C., Voigt, G., \& Corbett, C. J. (2019). Behavioral contract design under asymmetric forecast information. Decision Sciences, 50(4), 786-815.

Kar, A. K. (2014). Revisiting the supplier selection problem: An integrated approach for group decision support. Expert systems with applications, 41(6), 2762-2771.

Kar, A. K. (2015). A hybrid group decision support system for supplier selection using analytic hierarchy process, fuzzy set theory and neural network. Journal of Computational Science, 6, 23-33.

Kar, A. K. (2016). Bio inspired computing-a review of algorithms and scope of applications. Expert Systems with Applications, 59, 20-32.

Karami, A., Lundy, M., Webb, F., \& Dwivedi, Y. K. (2020). Twitter and Research: A Systematic Literature Review Through Text Mining. IEEE Access, 8, 67698-67717.

Karmarkar, U. S., \& Apte, U. M. (2007). Operations management in the information economy: Information products, processes, and chains. Journal of Operations Management, 25(2), 438-453.

Kostoff, R. N., \& Schaller, R. R. (2001). Science and technology roadmaps. IEEE Transactions on engineering management, 48(2), 132-143.

Kühl, N., Mühlthaler, M., \& Goutier, M. (2019). Supporting customer-oriented marketing with artificial intelligence: automatically quantifying customer needs from social media. Electronic Markets. DOI: https://doi.org/10.1007/s12525-019-00351-0

Kumar, S., Morstatter, F., \& Liu, H. (2014). Twitter data analytics. (pp. 1041-4347). New York: Springer.

Kumar, V., Rajan, B., Venkatesan, R., \& Lecinski, J. (2019). Understanding the role of artificial intelligence in personalized engagement marketing. California Management Review, 61(4), 135-155. 
Lee, H. H., Zhou, J., \& Hsu, P. H. (2015). The role of innovation in inventory turnover performance. Decision Support Systems, 76, 35-44.

Lee, H. K., \& Fernando, Y. (2015). The antecedents and outcomes of the medical tourism supply chain. Tourism Management, 46, 148-157.

Li, J. J., Bonn, M. A., \& Ye, B. H. (2019). Hotel employee's artificial intelligence and robotics awareness and its impact on turnover intention: The moderating roles of perceived organizational support and competitive psychological climate. Tourism Management, 73, 172-181.

Librantz, A. F., de Araújo, S. A., Alves, W. A., Belan, P. A., Mesquita, R. A., \& Selvatici, A. H. (2017). Artificial intelligence based system to improve the inspection of plastic mould surfaces. Journal of Intelligent Manufacturing, 28(1), 181-190.

Liu, C., Xiang, X., \& Zheng, L. (2020). Value of information sharing in a multiple producers-distributor supply chain. Annals of Operations Research, 285(1-2), 121-148.

Maldonado, S., González-Ramírez, R. G., Quijada, F., \& Ramírez-Nafarrate, A. (2019). Analytics meets port logistics: A decision support system for container stacking operations. Decision Support Systems, 121, 8493.

Manita, R., Elommal, N., Baudier, P., \& Hikkerova, L. (2020). The digital transformation of external audit and its impact on corporate governance. Technological Forecasting and Social Change, 150, 119751.

Matilda Bez, S., \& Chesbrough, H. (2020). Competitor Collaboration Before a Crisis: What the Al Industry Can Learn The Partnership on Al can use the Dynamic Capabilities Framework and lessons from other industries to proactively identify Al risks and create solutions. Research-Technology Management, 63(3), 42-48.

Metcalf, L., Askay, D. A., \& Rosenberg, L. B. (2019). Keeping humans in the loop: pooling knowledge through artificial swarm intelligence to improve business decision making. California Management Review, 61(4), 84-109.

Milas, G., \& Mlačić, B. (2007). Brand personality and human personality: Findings from ratings of familiar Croatian brands. Journal of Business Research, 60(6), 620-626.

Mishra, N., \& Singh, A. (2018). Use of twitter data for waste minimisation in beef supply chain. Annals of Operations Research, 270(1-2), 337-359.

Morikawa, M. (2017). Firms' expectations about the impact of ai and robotics: evidence from a survey. Economic Inquiry, 55(2), 1054-1063.

Mou, S., \& Robb, D. J. (2019). Real-Time Labour Allocation in grocery stores: A simulation-based approach. Decision Support Systems, 124, 113095.

Muggy, L., \& Stamm, J. L. H. (2020). Decentralized beneficiary behavior in humanitarian supply chains: models, performance bounds, and coordination mechanisms. Annals of Operations Research, 284(1), 333365. 
Naderpour, M., Lu, J., \& Zhang, G. (2014). An intelligent situation awareness support system for safetycritical environments. Decision Support Systems, 59, 325-340.

Nooralahzadeh, F., Arunachalam, V., \& Chiru, C. G. (2013). 2012 Presidential Elections on Twitter--An Analysis of How the US and French Election were Reflected in Tweets. In Control Systems and Computer Science (CSCS), 2013 19th International Conference on (pp. 240-246). IEEE.

Oh, S., Byon, Y. J., Jang, K., \& Yeo, H. (2015). Short-term travel-time prediction on highway: a review of the data-driven approach. Transport Reviews, 35(1), 4-32.

Overgoor, G., Chica, M., Rand, W., \& Weishampel, A. (2019). Letting the computers take over: using Al to solve marketing problems. California Management Review, 61(4), 156-185.

Peiris, K. D. A., Jung, J., \& Gallupe, R. B. (2015). Building and evaluating ESET: A tool for assessing the support given by an enterprise system to supply chain management. Decision Support Systems, 77, 41-54.

Petrovic, S. (2019). "You have to get wet to learn how to swim" applied to bridging the gap between research into personnel scheduling and its implementation in practice. Annals of Operations Research, 275(1), 161-179.

Queiroz, M. M., \& Telles, R. (2018). Big data analytics in supply chain and logistics: an empirical approach. The International Journal of Logistics Management, 29(2), 767-783.

Queiroz, M. M., \& Wamba, S. F. (2019). Blockchain adoption challenges in supply chain: An empirical investigation of the main drivers in India and the USA. International Journal of Information Management, $46,70-82$.

Rathore, A. K., Kar, A. K., \& Ilavarasan, P. V. (2017). Social media analytics: Literature review and directions for future research. Decision Analysis, 14(4), 229-249.

Romero, M., Guédria, W., Panetto, H., \& Barafort, B. (2020). Towards a characterisation of smart systems: A systematic literature review. Computers in Industry, 120, 103224.

Santiváñez, J. A., \& Melachrinoudis, E. (2020). Reliable maximin-maxisum locations for maximum service availability on tree networks vulnerable to disruptions. Annals of Operations Research, 286, 669-701.

Saraph, J. V., Benson, P. G., \& Schroeder, R. G. (1989). An instrument for measuring the critical factors of quality management. Decision sciences, 20(4), 810-829.

Shi, Z., \& Wang, G. (2018). Integration of big-data ERP and business analytics (BA). The Journal of High Technology Management Research, 29(2), 141-150.

Shrestha, Y. R., Ben-Menahem, S. M., \& Von Krogh, G. (2019). Organizational Decision-Making Structures in the Age of Artificial Intelligence. California Management Review, 61(4), 66-83.

Singh, A., \& Tucker, C. S. (2017). A machine learning approach to product review disambiguation based on function, form and behavior classification. Decision Support Systems, 97, 81-91.

Singh, J. P., Dwivedi, Y. K., Rana, N. P., Kumar, A., \& Kapoor, K. K. (2019). Event classification and location prediction from tweets during disasters. Annals of Operations Research, 283 (1-2), 737-757. 
Subramanian, N., \& Ramanathan, R. (2012). A review of applications of Analytic Hierarchy Process in operations management. International Journal of Production Economics, 138(2), 215-241.

Sun, T. (2019). Applying deep learning to audit procedures: An illustrative framework. Accounting Horizons, 33(3), 89-109.

Taylor, S. A., Hunter, G. L., Zadeh, A. H., Delpechitre, D., \& Lim, J. H. (2019). Value propositions in a digitally transformed world. Industrial Marketing Management. DOI: 10.1016/j.indmarman.2019.10.004

Thompson, R. L., Higgins, C. A., \& Howell, J. M. (1991). Personal computing: toward a conceptual model of utilization. MIS quarterly, 125-143.

Tierney, K., Áskelsdóttir, B., Jensen, R. M., \& Pisinger, D. (2015). Solving the liner shipping fleet repositioning problem with cargo flows. Transportation Science, 49(3), 652-674.

Vickranth, V., Bommareddy, S.S.R., \& Premalatha, V. (2019). Application of lean techniques, enterprise resource planning and artificial intelligence in construction project management. International Journal of Recent Technology and Engineering, 7(6C2), 147-153.

Wamba, S. F., \& Mishra, D. (2017). Big data integration with business processes: a literature review. Business Process Management Journal. 23(3), 477-492.

Wamba, S. F., \& Queiroz, M. M. (2020). Blockchain in the operations and supply chain management: Benefits, challenges and future research opportunities. International Journal of Information Management, 52, 102064.

Wamba, S. F., Akter, S., Edwards, A., Chopin, G., \& Gnanzou, D. (2015). How 'big data'can make big impact: Findings from a systematic review and a longitudinal case study. International Journal of Production Economics, 165, 234-246.

Wamba, S. F., Edwards, A., \& Akter, S. (2019). Social media adoption and use for improved emergency services operations: the case of the NSW SES. Annals of Operations Research, 283(1-2), 225-245.

Wamba, S. F., Gunasekaran, A., Akter, S., Ren, S. J. F., Dubey, R., \& Childe, S. J. (2017). Big data analytics and firm performance: Effects of dynamic capabilities. Journal of Business Research, 70, 356-365.

Wang, P., Sun, L., Niraj, R., Chung, J., \& Su, M. (2019). Incorporating reference products into modeling consumer choice decision: A mixtures-of-experts model. Decision Support Systems, 119, 85-95.

Warner, K. S., \& Wäger, M. (2019). Building dynamic capabilities for digital transformation: An ongoing process of strategic renewal. Long Range Planning, 52(3), 326-349.

Wooten, J. O., \& Tang, C. S. (2018). Operations in Space: Exploring a New Industry. Decision Sciences, 49(6), 999-1023.

Zangiacomi, A., Pessot, E., Fornasiero, R., Bertetti, M., \& Sacco, M. (2020). Moving towards digitalization: A multiple case study in manufacturing. Production Planning \& Control, 31(2-3), 143-157.

Zhang, Z. H., Berenguer, G., \& Shen, Z. J. (2015). A capacitated facility location model with bidirectional flows. Transportation Science, 49(1), 114-129. 
Zhao, Y., Cui, N., \& Tian, W. (2020). A two-stage approach for the critical chain project rescheduling. Annals of Operations Research, 285(1), 67-95. 